\title{
Review of Conjugated Porphyrin Systems
}

\section{Supriya S. , Vijayendra S. Shetti and Gurumurthy Hegde}

Porphyrin macromolecules play critical roles in many natural processes. Studies are going on to mimic their role in natural systems and use them in various applications in artificial systems. When a porphyrin moiety is conjugated with carbon nanoallotropes, viz., carbon nanomaterials, carbon nanotubes, carbon nanospheres, etc., the hybrid molecules show optimized properties compared to the pristine molecules. In this review, various mechanisms of conjugating carbon nanoallotropes/carbon nanomaterials and porphyrins through stable chemical bond formation are discussed. The non-covalent interactions which cause their aggregation without disrupting their electronic structures are also discussed. This review also gives vital information on the utilization of conjugated systems effectively for society oriented applications.

\section{Introduction}

\subsection{Porphyrins}

Porphyrins are naturally occurring colored compounds ubiquitously found in nature as chlorin in chlorophyll pigments, as heme in hemoglobin, as corrin in vitamin $\mathrm{B}_{12}$, etc. ${ }^{1-5}$ Some of the important fundamental biological roles played by these "pigments of life" are oxygen storage and transport in myoglobin and hemoglobin, respectively, electron transfer in cytochromes, and radical generation in photosynthesis. $\stackrel{-6}{-}$ Chemically, a porphyrin is a tetrapyrrolic aromatic macrocyclic compound with an $18 \pi$-conjugated electronic system.

The pyrrole rings of porphyrins are connected at the $\alpha$ position by methine bridges $\underline{10}$ (Fig. 1). The two other important regions of the porphyrin structure are $\beta$ and meso positions where functionalization can be carried out. A porphyrin's macrocyclic cavity can act as a tetradentate ligand resulting from four pyrrole nitrogen atoms and can host a wide array of metal ions. 11 The other members of the porphyrinoid family include the "contracted" and "expanded" versions of porphyrins which have contrasting properties compared to "normal" porphyrins. .2 The replacement of one or more inner pyrrole ring(s) of normal, contracted and expanded porphyrins by heterocycles such as furans, thiophenes, and selenophenes leads to "core-modified" versions of these macrocycles with interesting properties. $\frac{13-15}{25}$ 


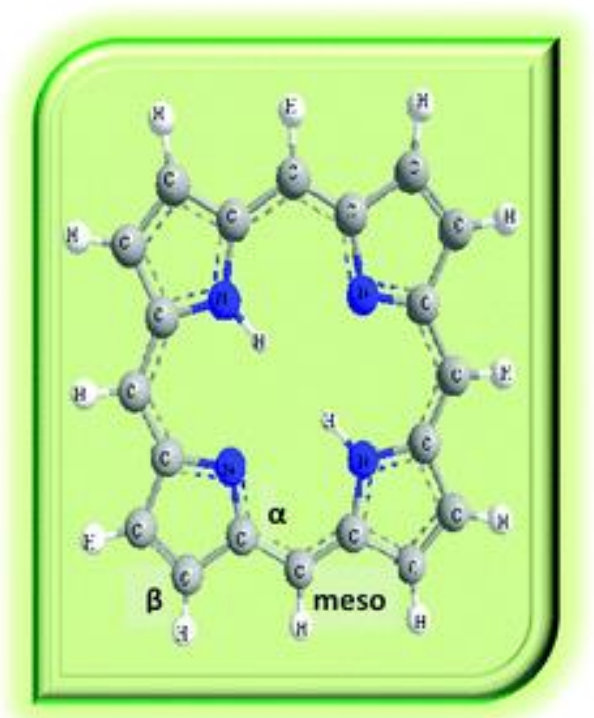

Fig. 1 Porphyrin structure showing $\alpha, \beta$ and meso positions.

The laboratory synthesis of porphyrins generally involves a condensation reaction between aldehydes and pyrroles based on Adler-Longo' ${ }^{16}$ or Lindsey's ${ }^{17}$ protocols. Adler-Longo's process makes use of harsh reaction conditions like refluxing starting materials in propionic acid, whereas Lindsey's method is based on the Lewis acid catalyzed reaction of pyrroles and aldehydes in low boiling solvents at room temperature followed by oxidation with DDQ/Chloranil. The striking feature of synthetic porphyrins is their aromatic character which is well evident from ${ }^{1} \mathrm{H}$ NMR spectra. For example, meso-5,10,15,20-(tetratolyl)porphyrin, $\mathrm{H}_{2} \mathrm{TTP}$, obtained by condensation of pyrrole and $p$-tolualdehyde exhibits downfield shifted $\beta$-pyrrole proton resonances at $\sim 8.8 \mathrm{ppm}$ and highly upfield shifted resonances for core $\mathrm{NH}$ protons at $\sim-2.7 \mathrm{ppm}$. These observations indicate the aromatic ring current effect operating due to the planar conjugated electronic system of the porphyrin skeleton. ${ }^{18}$ Porphyrins exhibit very attractive absorption and emission characteristics in the UV-vis-NIR region. The typical absorption spectrum of free base porphyrin $\mathrm{H}_{2}$ TTP has strong absorption around $400 \mathrm{~nm}$ (Soret band, extinction coefficient value $>2 \times 10^{5}$ ) and four absorption bands in the 500-700 $\mathrm{nm}$ regions (Q-bands) as explained by the Gouterman Four-Orbital model. ${ }^{20}$ The free base porphyrin, $\mathrm{H}_{2} \mathrm{TTP}$, also exhibits strong fluorescence around 600-800 nm. ${ }^{21}$ Porphyrins generally are attractive from an electrochemical perspective and their redox properties can be tuned by varying the substituents on the meso/ $\beta$ positions, metallation and core-modification. 22

Porphyrins/metalloporphyrins and their derivatives have been used as excellent photosensitizers in dye-sensitized solar cell (DSSC) applications 23 and photodynamic therapy (PDT); $; 4$ as catalysts for chemical transformations including asymmetric synthesis; 25 in supramolecular chemistry ${ }^{26}$ and organic electronics,, 27.28 etc.

\subsection{Carbon nanoallotropes (CNAs)}

CNAs are structures with sizes $<100 \mathrm{~nm}^{29.30}(0.1 \mathrm{~mm})$ at least in one dimension. Many forms of carbon nanoallotropes (Fig. 2) have been developed in the past few decades. Some of them are tubes, dots, fullerenes, graphene, nanohorns, nanodiamonds, etc. $\frac{31-33}{3}$ These allotropes exhibit exciting structural and functional properties that can be converted into several intriguing applications. Briefly, carbon nanomaterials exhibit extraordinary electrical, ${ }^{34}$ thermal, mechanical, ${ }_{35.36}$ chemical, ${ }_{37.38}$ optical, ${ }^{39}$ nuclear (magnetic) ${ }^{40}$ and biological properties. ${ }^{41-43}$ All these 
properties in one material were merely impossible to imagine few years back but now it has become a reality. The major contribution behind this paragon is their high surface area to volume ratios. ${ }^{44.45}$ The other reason can be the hybridization state of the carbon atoms in the structure. Carbon orbitals can undergo $\mathrm{sp}, \mathrm{sp}^{2}$ or $\mathrm{sp}^{3}$ hybridization based on bonding suitability.

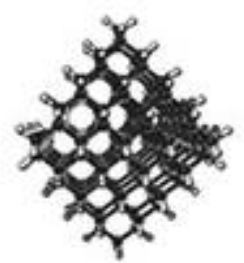

Nanodiamond

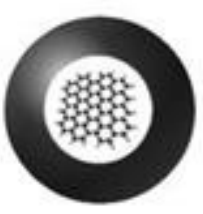

Carbon Dots

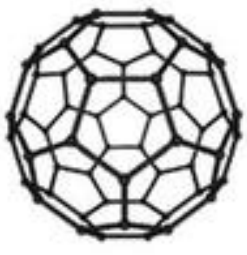

Fullerene C60

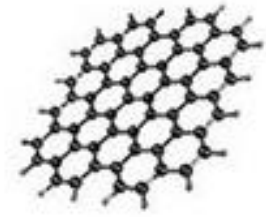

Graphene

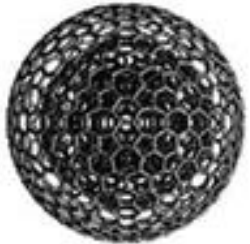

Carbon Onion

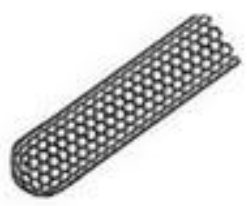

SWNT

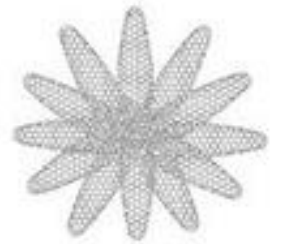

Nanohorn

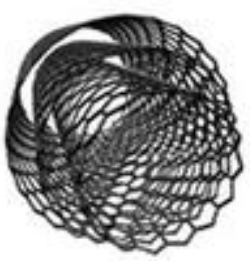

MWNT

Fig. 2 Different forms of carbon nanostructures. 19

1.2.1 Carbon nanotubes (CNTs). CNTs are 1-dimensional (1D) ${ }^{46}$ cylindrical macromolecules with diameters in the nanoscale; single walled carbon nanotubes (SWCNTs) can have a diameter of 1-2 $\mathrm{nm}^{47}$ and multiwalled carbon nanotubes (MWCNTs) which contain multiple numbers of carbon layers can have a diameter between 2 and $100 \mathrm{~nm} . \underline{48}$ The walls of CNTs are made up of $\mathrm{sp}^{2}$ hybridized ${ }^{49}$ carbon atoms arranged in a hexagonal lattice. The shape can be modified as bent or twisted by incorporating pentagonal or heptagonal rings into their structures..$^{50}$ Researchers have made many successful attempts to functionalize CNTs at their surfaces which not only preserved their original qualities but also added optimized properties.

1.2.2 Carbon dots (CDs). CDs are 0D quasi-spherical ${ }^{51}$ shaped nanostructures with diameters between 2 and $10 \mathrm{~nm} \cdot \frac{52.53}{} \mathrm{CDs}$ are usually amorphous in nature containing $\mathrm{sp}^{3}$ hybridized ${ }^{54}$ carbon atoms. The nano-size and surface modifications impart photoluminescence ${ }^{\frac{55}{5}}$ properties to CDs significantly.

1.2.3 Fullerenes. Fullerenes, also called buckyballs or buckminsterfullerenes, are ball-like structures made up of a mixture of $\mathrm{sp}^{2}$ and $\mathrm{sp}^{3}$ hybridized carbon atoms. ${ }^{.6}$ In these 0D structures, carbon atoms are arranged to form either 5-membered or 6-membered rings which then develop like a closed hollow cage. ${ }^{57}$ The size of fullerenes varies depending on the number of carbon atoms (from 60 to 100$). \frac{58}{-}$ The most abundant and simplest fullerene $\left(\mathrm{C}_{60}\right)$ has an external diameter of $0.71 \mathrm{~nm}$, and 12 pentagonal and 20 hexagonal rings. .99 The void in their cage and fullerene surface is suitable for functionalization and thus holds excellent possibilities of applications.

1.2.4 Graphene. Graphene is a $2 \mathrm{D}$, planar sheet of $\mathrm{sp}^{2}$ carbon atoms that are linked via covalent sigma bonds. 60 The layers of graphene (2-10) can pile, forming thick multilayered graphitic nanosheets. Graphene exhibits an aromatic nature due to the flow of electrons through sideways overlapped unhybridized p-orbitals. Graphene also forms 1D nanoribbons, which appear as 
unzipped CNTs, with widths of $<50 \mathrm{~nm} \cdot{ }^{61}$ Their excellent conducting properties can be made use of in varieties of applications.

1.2.5 Carbon nanohorns (CNHs). Nanohorns are another class of carbon nanoallotropes, gaining much attention nowadays. They are horn shaped, which aggregate to form dahlia like structures with an average cone angle of $120^{\circ} .{ }^{62.63}$ Generally, the diameter of these aggregates is in the 50$100 \mathrm{~nm}$ range, whereas the diameter of each cone is $2-5 \mathrm{~nm}$. The cone can grow up to a length of 40-50 nm. ${ }^{64}$ Nanohorns are the known purest form of carbon nanomaterials because they are obtained from pure graphite rods by laser ablation or arc discharge methods without any involvement of metal catalysts. $\frac{65}{}$

1.2.6 Carbon nanospheres (CNSs). Nanospheres are spherical shaped carbon nanoparticles with a hollow space at their center. 6 The carbon nanospheres possess randomly arranged carbon layers; their size can vary based on the graphitic nature of the particles. A carbon nanosphere with well graphitized layers has a diameter ranging from $2 \mathrm{~nm}$ to $20 \mathrm{~nm}$, whereas a poorly graphitized carbon nanosphere will be bigger in size with a diameter of $50 \mathrm{~nm}$ to $1 \mu \mathrm{m}$. A carbon bead has distorted layers; therefore it exhibits larger diameters, i.e., more than $1 \mu \mathrm{m} .{ }^{67}$ The research work done in this field is latent; therefore this provides large opportunities to explore intriguing facts and possibilities of CNSs' applications in various fields.

Several top-down and bottom-up approaches have been developed to synthesize CNAs. A top-down method is a disintegration process where a bulk material is converted into minute particles. It includes pyrolysis, ${ }^{68-71}$ electric discharge,,$\frac{72-74}{}$ laser ablation,, 5.76 decomposition processes,,$\frac{77.78}{}$ etc.; whereas a bottom-up approach focuses on the formation of materials from the atomic level; like chemical vapor deposition (CVD), ${ }^{79.80}$ physical vapor deposition (PVD), ${ }^{81.82}$ hydrothermal methods, ${ }^{83.84}$ etc. Now, scientists are aiming at producing CNs via catalyst free, template free procedures that require no chemical reagents or that require their minimum usage.

With exorbitant surface areas, CNAs are amenable to functionalization at their surface and interior doping. The properties of CNAs having modified surfaces are well enhanced in comparison with the pristine materials. These properties have provided a wide platform for innumerous applications.

For many years, researchers have been utilizing these tiny structures in electronic devices $; \underline{85}$ energy technologies such as solar cells; $; \underline{86}$ energy storage; $; \underline{87}$ biomedical applications like

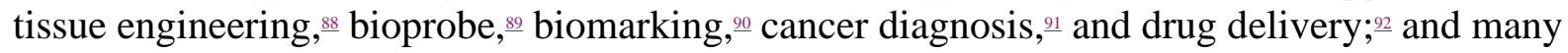
more. Having gained a unique place in the field of nanoscience, the era of CNAs has been propagated, followed by a tremendous increase of research activity in this field. This review focuses on the recent trends in covalent/non-covalent synthetic approaches towards the creation of porphyrin-CNM hybrids and their application in various fields.

\subsection{Porphyrin-carbon nanomaterial hybrids}

Porphyrins and CNAs have received great attention in research recently due to their excellent structural and functional properties. As individual materials, they have proved their significance in various fields of applications. Looking at these two materials, it is noticeable that they showcase distinct physical, chemical and biological features. In brief, the dominant character of porphyrins is their photosensitivity, whereas CNAs possess huge surface area. So, it is fascinating to bring together the attractive qualities of these two materials. In this regard, the era of immobilizing porphyrins onto different carbon nanoallotropes has started.

In the past few years, conjugation of porphyrins and carbon nanomaterials has emerged as an interesting topic of research because of their fascinating improved properties compared to the 
individual compounds. CNAs are functionalised with porphyrins either covalently or noncovalently, which will be discussed further in this review. Covalent interactions provide thermodynamically stable structures, but the electronic structures of the pristine compounds are disturbed during bond formation; whereas non-covalent functionalization is based on secondary interactions such as $\pi-\pi$ interactions, electrostatic interactions, hydrogen bonding, etc., and the advantage here is that the non-covalent approach does not disrupt the intrinsic electronic structure of the nanomaterial but keeps it intact. But the stability is proved to be comparatively low. The type of interaction between a porphyrin and a carbon nanomaterial can be chosen based on certain application requirements.

1.3.1 Porphyrin-carbon nanotube (CNT) hybrids. Porphyrins can be immobilized onto CNTs via covalent or noncovalent strategies. In covalent approaches, CNTs are first activated to obtain functional groups at their surfaces; the surface functionalized CNTs are then treated with porphyrins, which results in stable bond formation between them. Both single walled CNTs (SWCNTs) and multiwalled CNTs (MWCNTs) can be used for hybrid formation with porphyrins. In one such method, a hybrid of 5-( $p$-hydroxyphenyl)-10,15,20-tritolylporphyrin (Por-OH) and carboxyl group functionalized CNTs is prepared via ester linkages. ${ }^{24}$ The CNTs are initially subjected to wet-air oxidation, followed by sulfuric acid and nitric acid in a $3: 1$ ratio. The process causes $-\mathrm{COOH}$ groups at the $\mathrm{CNT}$ surfaces. The carboxylic group functionalized CNTs are treated with thionyl chloride and then with excess Por-OH in toluene and triethylamine (TEA) at $100{ }^{\circ} \mathrm{C}$ for $24 \mathrm{~h}$ under a nitrogen atmosphere (Fig. 3). During the reaction, the $-\mathrm{COCl}$ on the CNTs and $\mathrm{OH}$ on the porphyrin undergo condensation, forming ester linkages between the pristine compounds. The unreacted Por-OH is removed by washing with a series of solvents, viz., methanol, acetic acid, triethylamine and tetrahydrofuran.

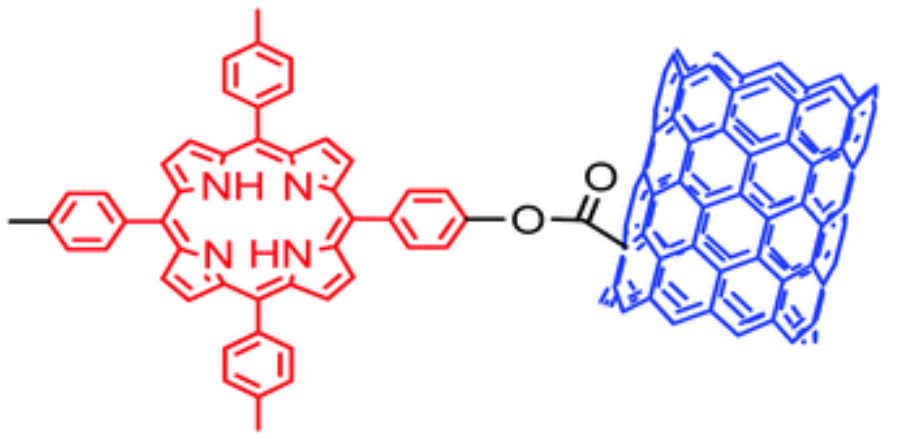

Fig. 3 Covalent conjugation between a CNT and a porphyrin via an ester linkage.

Another mode of porphyrin attachment onto CNTs is via amide linkages (Fig. 4). A supramolecular assembly of carboxylic functional group bearing porphyrins with aminefunctionalized $\mathrm{CNTS}^{0.596}$ can be structured by a simple condensation method. First, the carboxylic group of the porphyrin in dimethylformamide (DMF) is activated into an active carbodiimide ester group by adding dicyclohexylcarbodiimide (DCC). The amine-functionalized CNTs are then added to the reaction mixture at room temperature, followed by stirring for $48 \mathrm{~h}$. The carboxyl and amine groups undergo condensation resulting in a stable porphyrin-CNT hybrid via amide linkages. ${ }^{93.97}$ Any DCC intermediate by-products formed during the reaction are removed by washing the product with DMF. A similar type of hybrid can be formed by interchanging the functional groups. A porphyrin molecule with the amine group ${ }^{9.999} \mathrm{can}$ be used to form an amide linkage with an acid treated,,${ }^{100.101}-\mathrm{COOH}$ group containing CNT. 


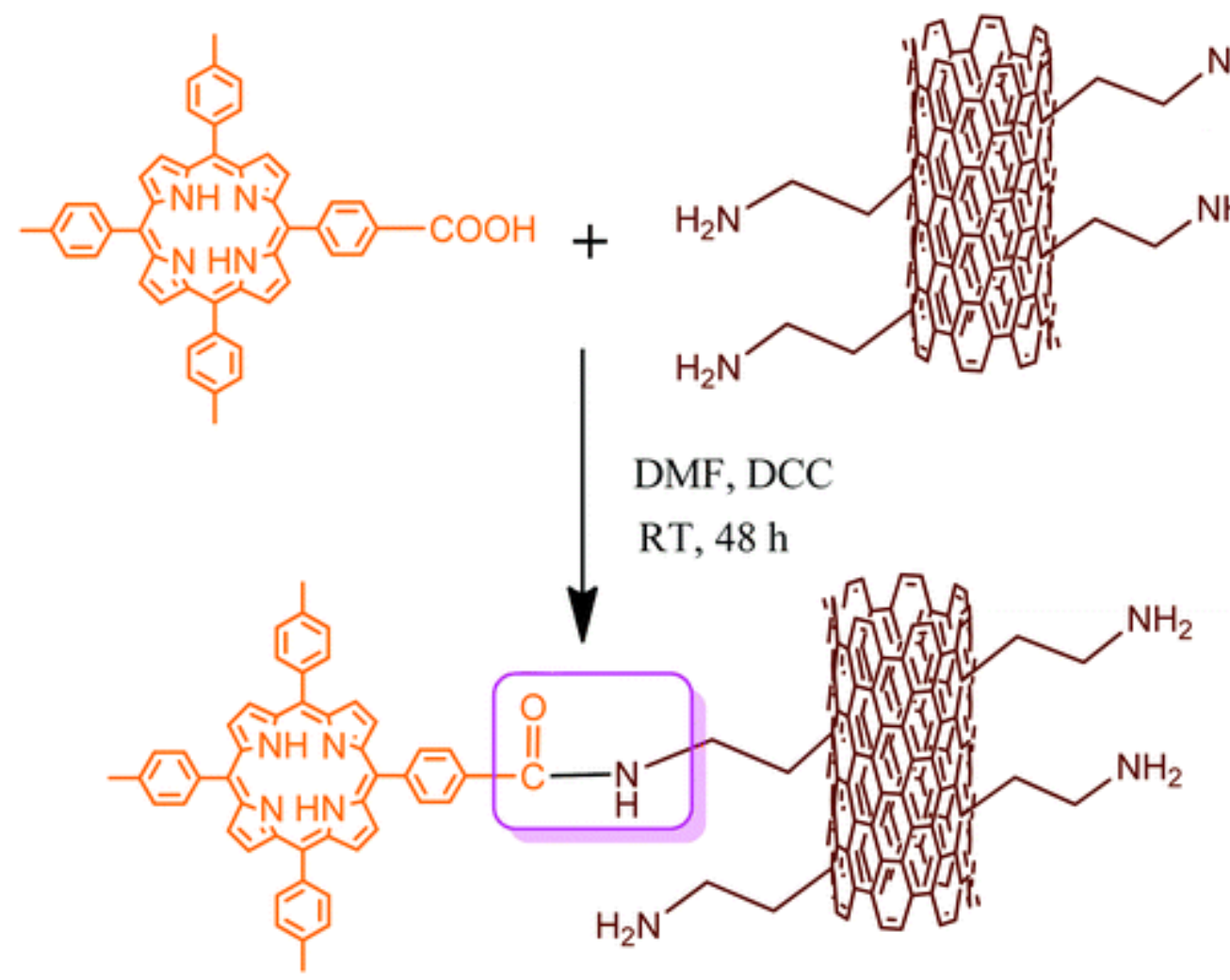

Fig. 4 Formation of an amide linkage between a porphyrin and a CNT. ${ }^{93}$

The surface modification of CNTs is favoured for their efficient covalent conjugation with porphyrins. The recent trend is to link CNTs with axially functionalized porphyrins. ${ }^{102}$ In this regard, 1,3-dipolar cycloaddition ${ }^{103,104}$ by a one pot Prato reaction ${ }^{105}$ and a stepwise approach leads to the formation of a CNT-porphyrin hybrid (Fig. 5) with improved solubility and processability. In the straightforward method, (5,10,15,20-tetraphenylporphyrinato)tin(IV) (SnTPP) and sarcosine are mixed with CNTs in DMF. The mixture is heated at $130{ }^{\circ} \mathrm{C}$ under $\mathrm{N}_{2}$. A portion of sarcosine and SnTPP is added to the reaction system every 24 hours for six days. The hybrid is formed and is isolated from the solution by pouring it into ice cold water. $\frac{106}{-6}$ 


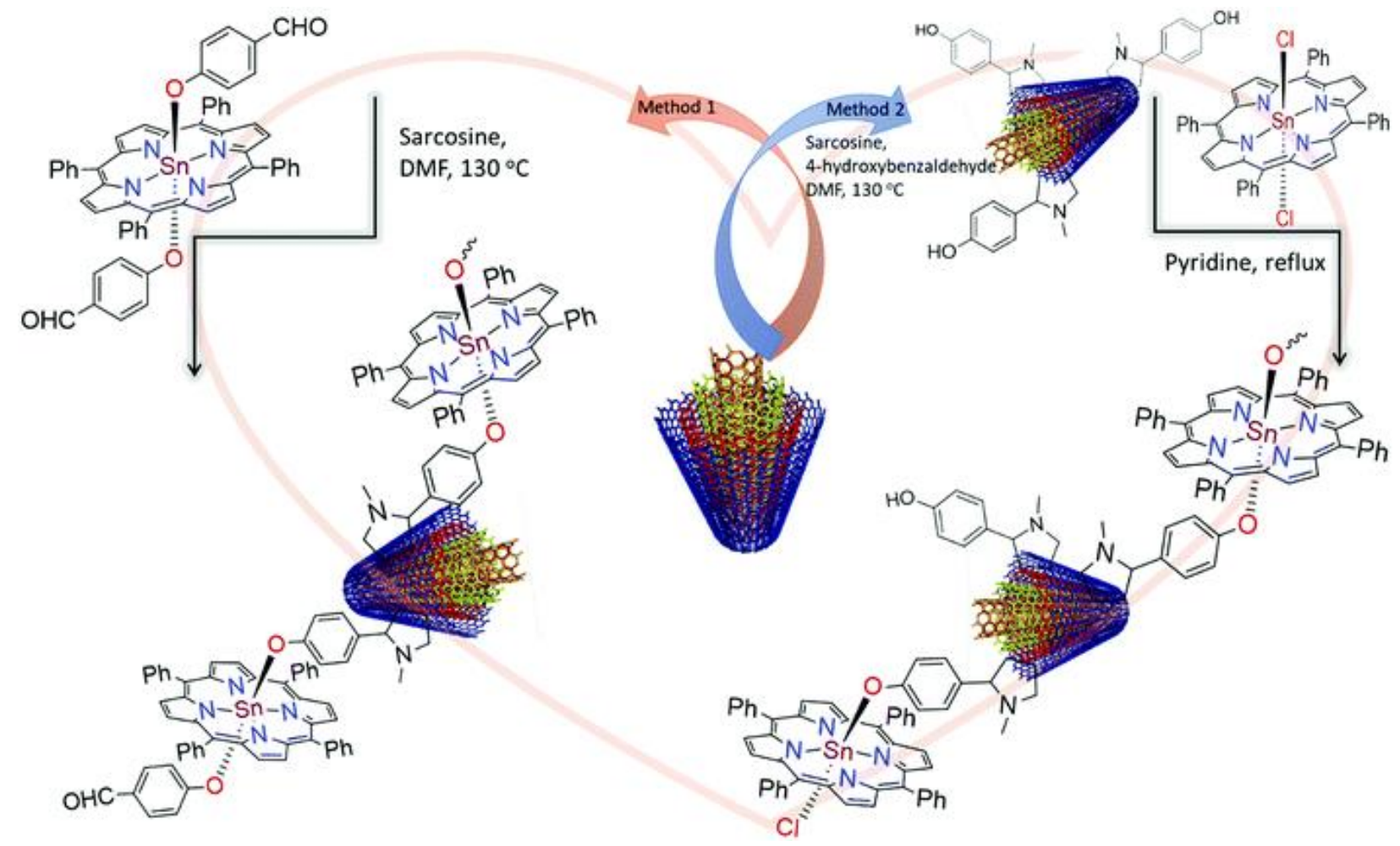

Fig. 5 Formation of a porphyrin-CNT hybrid by a one step Prato reaction and a stepwise 1,3-dipolar cycloaddit one pot Prato reaction; method 2: stepwise approach.

The stepwise approach involves functionalization of CNTs with 4-hydroxybenazaldehyde and then 1,3-dipolar cycloaddition with SnTPP. Functionalization of CNTs occurs when 4hydroxybenzaldehyde is added to CNTs in DMF and heated at $130{ }^{\circ} \mathrm{C}$ along with sarcosine. The 4-hydroxybenzaldehyde functionalized CNTs in pyridine are added to SnTPP under $\mathrm{N}_{2}$. A 1,3dipolar cycloaddition product is obtained by refluxing the mixture for four days, which is then isolated by filtration. ${ }^{106}$ The porphyrins and CNTs are conjugated by the Sonogashira coupling reaction; a reaction between tris-(triphenylamine)porphyrinato zinc(II) and single walled and double walled CNTs with iodobenzene functionalization is carried out under microwave irradiation conditions, which results in $\mathrm{C}-\mathrm{C}$ bonding between porphyrins and CNTs (Fig. 6$) .107 \mathrm{~A}$ $[3+2]$ cycloaddition reaction also favours the hybrid formation between porphyrins and CNTs. ${ }^{108.109}$ Pyridyl substituted double walled CNTs form supramolecular assemblies with zinc porphyrins. The pyridyl units are attached to the external walls of the CNTs through isoxazolino linkers and esters of carboxylic groups. At $0{ }^{\circ} \mathrm{C}$, nitrile oxide from 4-pyridylcarboxaldehyde oxime undergoes [3+2] cycloaddition reaction with $N$-chlorosuccinimide in situ, in the presence of pyridine. A solution of pentyl ester functionalized CNTs and triethylamine in $o$ dichlorobenzene is added, after removing the solvent, to the reaction mixture followed by microwave radiation treatment at $120 \mathrm{~W}$ for $45 \mathrm{~min}$. When the solvent is evaporated, the porphyrin-CNT hybrid is obtained as a solid residue. 


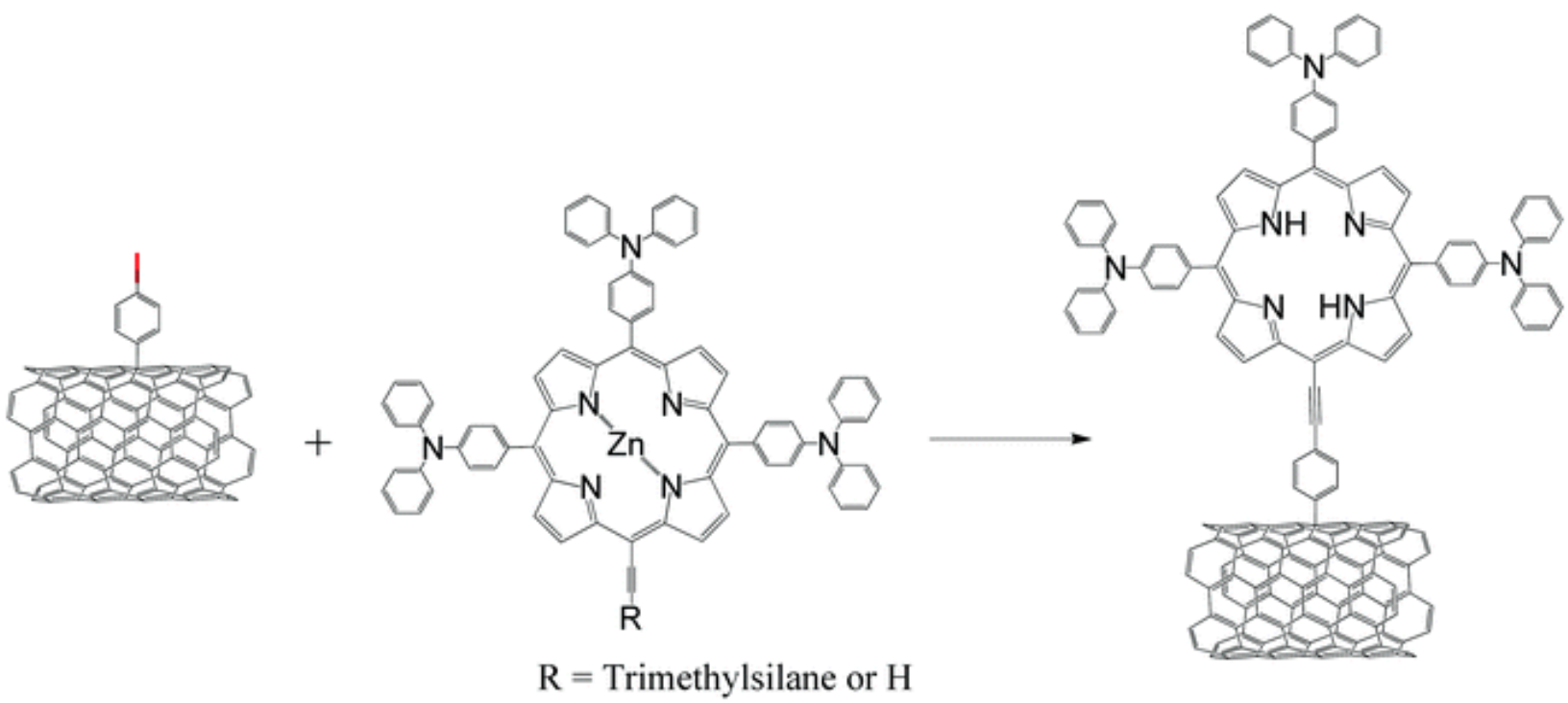

Fig. 6 Covalent linkage between tris-(triphenylamine)porphyrinato zinc(II) and an iodobenzene functionalized

The porphyrin can be immobilized onto CNTs via $\mathrm{S}_{\mathrm{N}} 2$ substitution to achieve zwitterionic functionalization by treating it with an electrophile (dichloroethyl acetylenedicarboxylate) and a nucleophile (4-dimethylaminopyridine (DMAP)) in $p$-dioxane at $95{ }^{\circ} \mathrm{C}$. When a cobalt porphyrin is added to a solution containing CNTs in $\mathrm{THF}$ at $90^{\circ} \mathrm{C}$, they undergo substitution reaction forming a hybrid. .110

Another interesting type of hybrid structure is a porphyrin polymer wrapped around CNTs. A reaction between metal free CNTs and porphyrins is conducted under hot conditions in DMF at $100{ }^{\circ} \mathrm{C}$. The heating is continued for an extended time, i.e., up to four days, until polymer wrap formation occurs. The formation of a hybrid is tested using absorption and fluorescence spectroscopic techniques. Temperature is found to play a major role in this experiment, as no characteristic results are obtained when the same procedure is followed at $200{ }^{\circ} \mathrm{C} .111$

It is clear that the covalent conjugation of porphyrins and CNTs results in stable hybrid structures with increased solubility or dispersion in solvents. But the electronic and/or structural properties of the pristine compounds are disturbed. Therefore, the composite mixtures of porphyrins and CNTs grab the attention which promises to retain the original qualities of the pristine compounds. Here, porphyrin molecules and CNTs assemble via non-covalent interactions, $\frac{112-114}{14}$ such as hydrogen bonding, electrostatic forces, $\pi-\pi$ stackings, etc.

One beautiful method found suitable to produce non-covalent conjugates of porphyrins and carbon nanotubes is by micelle formation as shown in Fig. 7. Both hydrophilic and hydrophobic porphyrins can be architectured with CNTs with the help of surfactants that create micelles. In the case of hydrophilic porphyrins, they themselves act as surfactants; whereas when hydrophobic porphyrins are used for hybrid formation, additional surfactants like sodium cholate have to be added. The hydrophobic porphyrins are first dissolved in suitable organic solvents such as dichloromethane and then mixed with a micellar solution of CNTs. The porphyrin molecules travel to the organic core of the micelle that contains CNTs. The two pristine compounds thus form assemblies via $\pi$ stacking interactions..$\frac{115}{1}$ 


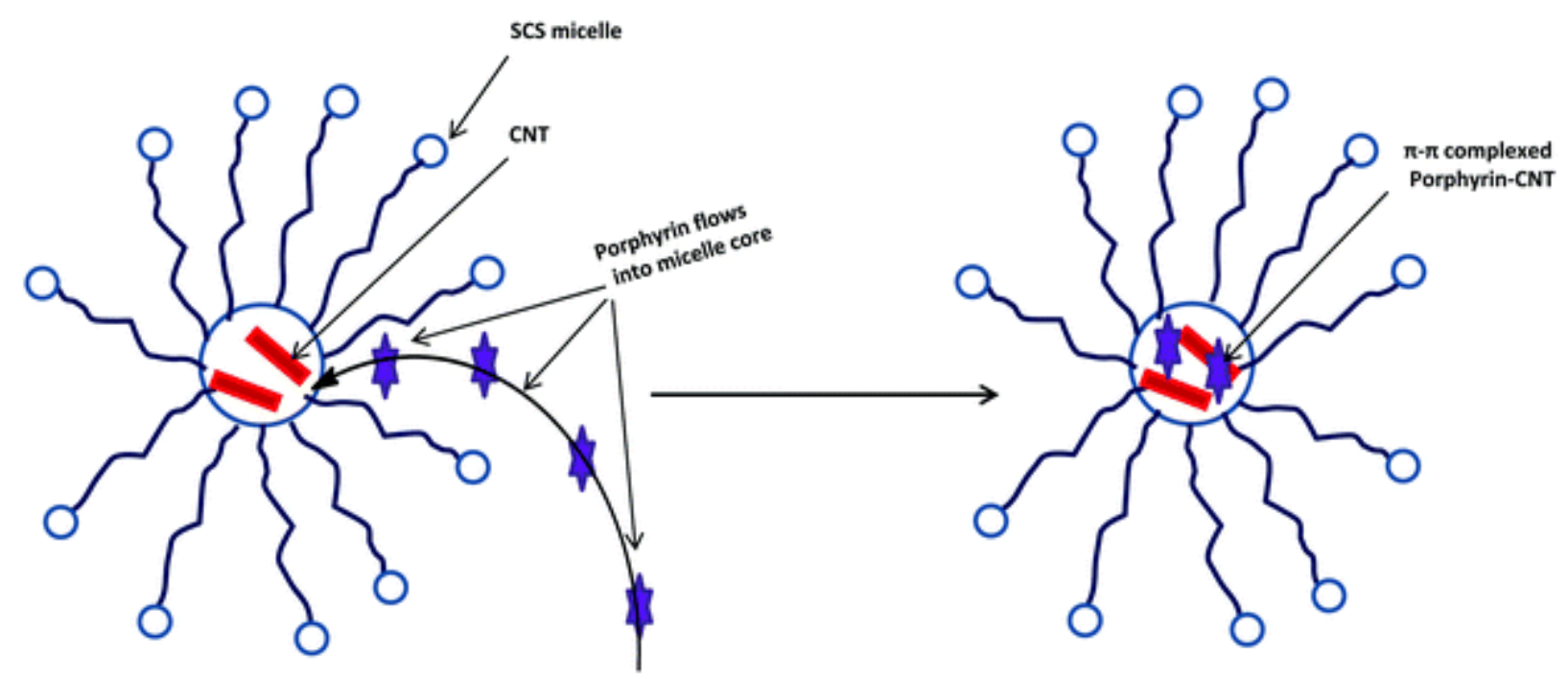

Fig. 7 Sketch of the noncovalent conjugation of porphyrins and CNTs by the micelle formation method. $\frac{115}{15}$

Composites of porphyrins and CNTs are possible via molecular interactions. Glycylsubstituted 5,10,15,20-tetraphenylporphyrin interacts with single walled CNTs at $85^{\circ} \mathrm{C}$, under a nitrogen atmosphere, in the presence of formaldehyde in DMF. The composite requires seven days to form after which it can be separated from the reaction system using dichloromethane (DCM). 117.118

The stability of the porphyrin-CNT hybrid is lowered when conjugated non-covalently, due to the lower affinity of the porphyrin towards the CNT surface. The reason behind the decreased interaction is the spatial distance between the porphyrin and CNT that retards the electronic coupling. $\frac{116,120}{}$ The stability of a non-covalent hybrid can be increased by increasing the proximity between the chromophore and CNT.

This is achieved using higher $\pi$ electronic structures such as porphyrins fused with polycyclic aromatic rings. $\frac{121-123}{2}$ An experiment conducted with bis-pyrenylporphyrin, mono-fused pyrenyl porphyrin and doubly fused pyrenyl porphyrins (Fig. 8) showed enhanced affinity of porphyrins to CNT sidewalls. The suspensions of the above mentioned porphyrins and CNTs are sonicated to get homogeneous solutions $\frac{124}{24}$ of hybrids. When checked for stability, a solution of a bispyrenyl porphyrin-CNT hybrid showed precipitation upon allowing it to stand for one hour, whereas in mono-fused porphyrin-CNT, the precipitation started after a week, indicating increased stability of the system. The stability of non-covalent conjugation as a function of $\pi$ interactions is well proved by doubly fused porphyrin-CNT, which remained stable displaying no sign of precipitation even after a week. $\stackrel{116}{ }$ 


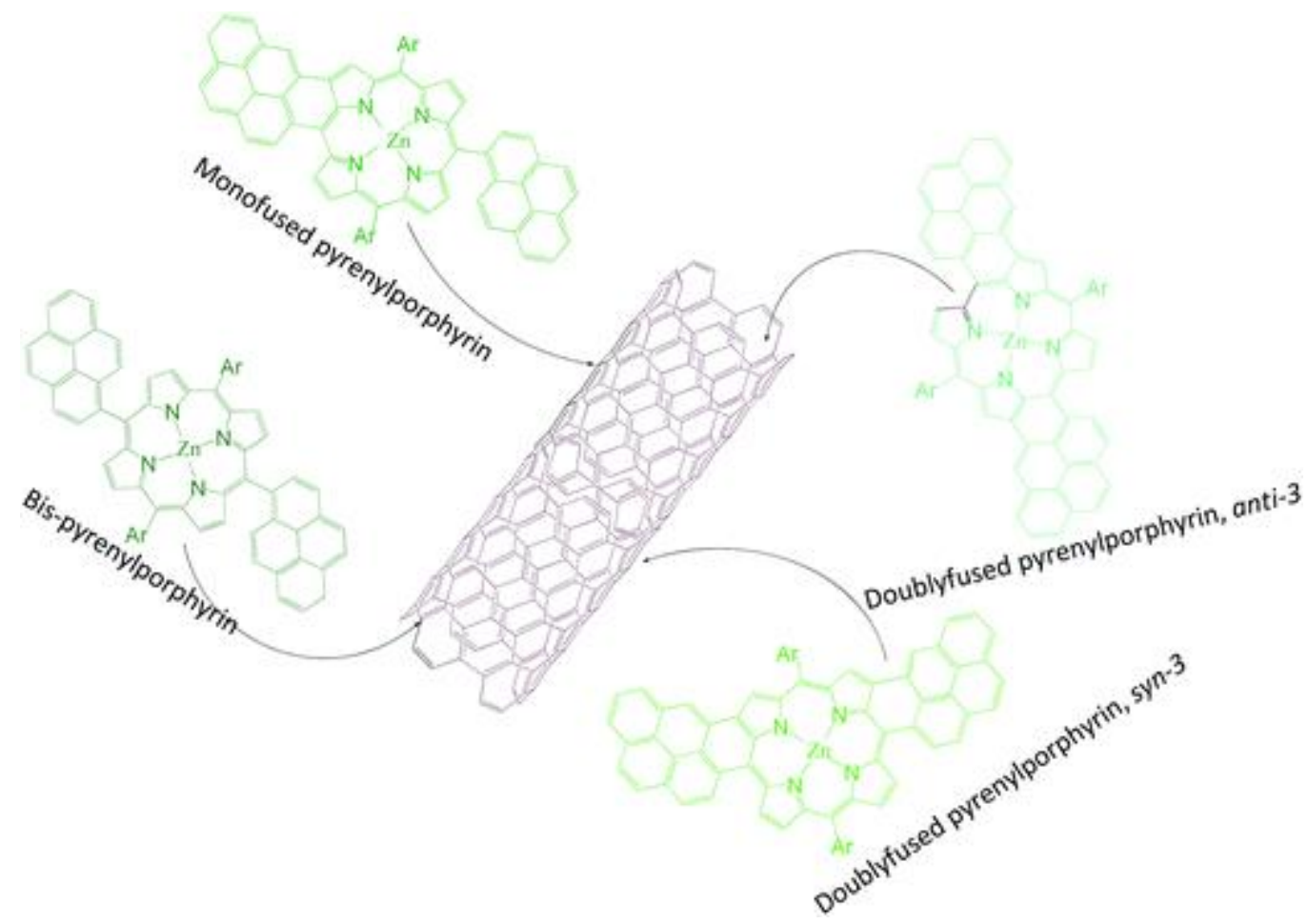

Fig. 8 Schematic representation of non-covalent conjugation between porphyrins with fused aromatic rings and

The allure of non-covalent conjugation is that it can immobilize porphyrins with various substituents on CNTs by simple procedures like sonication or stirring for a specific duration. Even porphyrins with long chain or bulky substituents can be attached to CNTs by these methods. For example, tetraphenylporphines with hexadecyloxyls, (10-undecenyl)oxyls having terminal alkenes, and (11-acetylthioundecyl)oxyls having terminal thioesters as substituents at the para-position are conjugated with CNTs via a simple sonication technique (Fig. 9). Solutions of pristine compounds in a $1: 1$ mass ratio are mixed in chloroform and sonicated at $15{ }^{\circ} \mathrm{C}$ constant temperature. The formation of a non-covalent hybrid is accompanied by a change of color from purple to green, with a gradual increase in color due to the efficient dispersion of CNTs in solvent followed by hybridization. The stability of the hybrid is analysed on the basis of the structural regularities of porphyrins bearing different substituents. The porphyrin with a structurally regular saturated alkane side chain is found to arrange in a more orderly manner compared to less regular terminal alkene and thioester bearing porphyrins. .19 


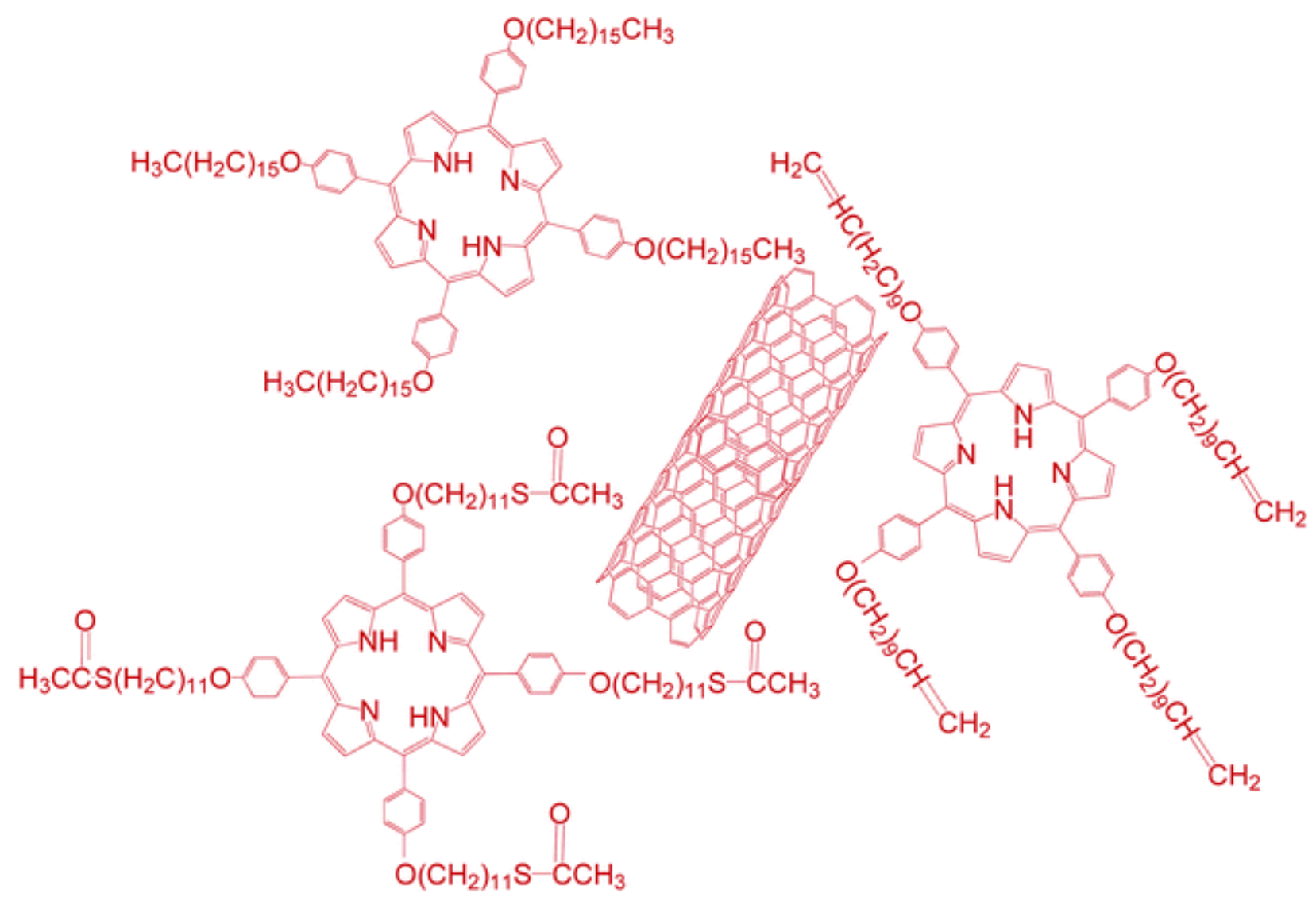

Fig. 9 Schematic representation of non-covalent assembly of terminal alkene and thioester substituted porphyri

1.3.2 Porphyrin-fullerene hybrids. Conjugation of porphyrins and fullerenes is an intriguing field to many researchers. Owing to the cage structured ball shape and geodesic $\pi$-system of fullerenes, it is fascinating to assemble them with other interesting molecules like porphyrins. Both porphyrins and fullerenes possess extended $\pi$ systems, capable of interacting with applied electric, ${ }^{125}$ magnetic ${ }^{126.127}$ and electromagnetic fields ${ }^{128.129}$ and also with a wide variety of chemical species. Together, they form an electron donor-acceptor system, with the porphyrin being the electron donor.

Many synthetic procedures have been developed over the decades to produce porphyrinfullerene supramolecular assemblies. $.132-138$

A more frequently spoken procedure is 'click chemistry', $\frac{139,140}{1,}$ where the complex hybrid is formed by a versatile and simple reaction. A 1,3-dipolar cycloaddition reaction (Fig. 10) between a fullerene bearing the acetylene group and an azide ${ }^{130.141}$ functionalized porphyrin (or an azide functionalized fullerene) leads to the formation of a chromophoric hybrid. 


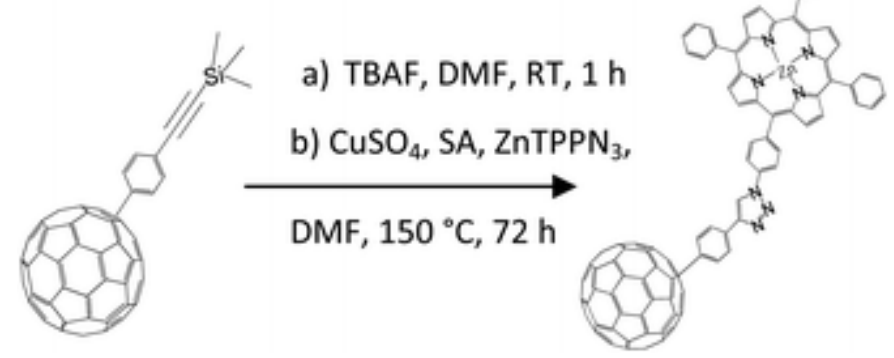

Fig. 10 Click reaction showing the formation of a porphyrin-fullerene hybrid. $\frac{130}{10}$

Porphyrin-fullerene hybrids can also be synthesized via [4+2] cycloaddition reaction. $\stackrel{131}{ }$ Tetraphenylporphine, the starting material, is modified to 5-(4-nitrophenyl)-10,15,20triphenylporphyrin, followed by reaction with the carbanion of chloromethyl $p$-tolyl sulphone, forming the product with the $\mathrm{CH}_{2} \mathrm{SO}_{2}$ Tol group (Fig. 11). 

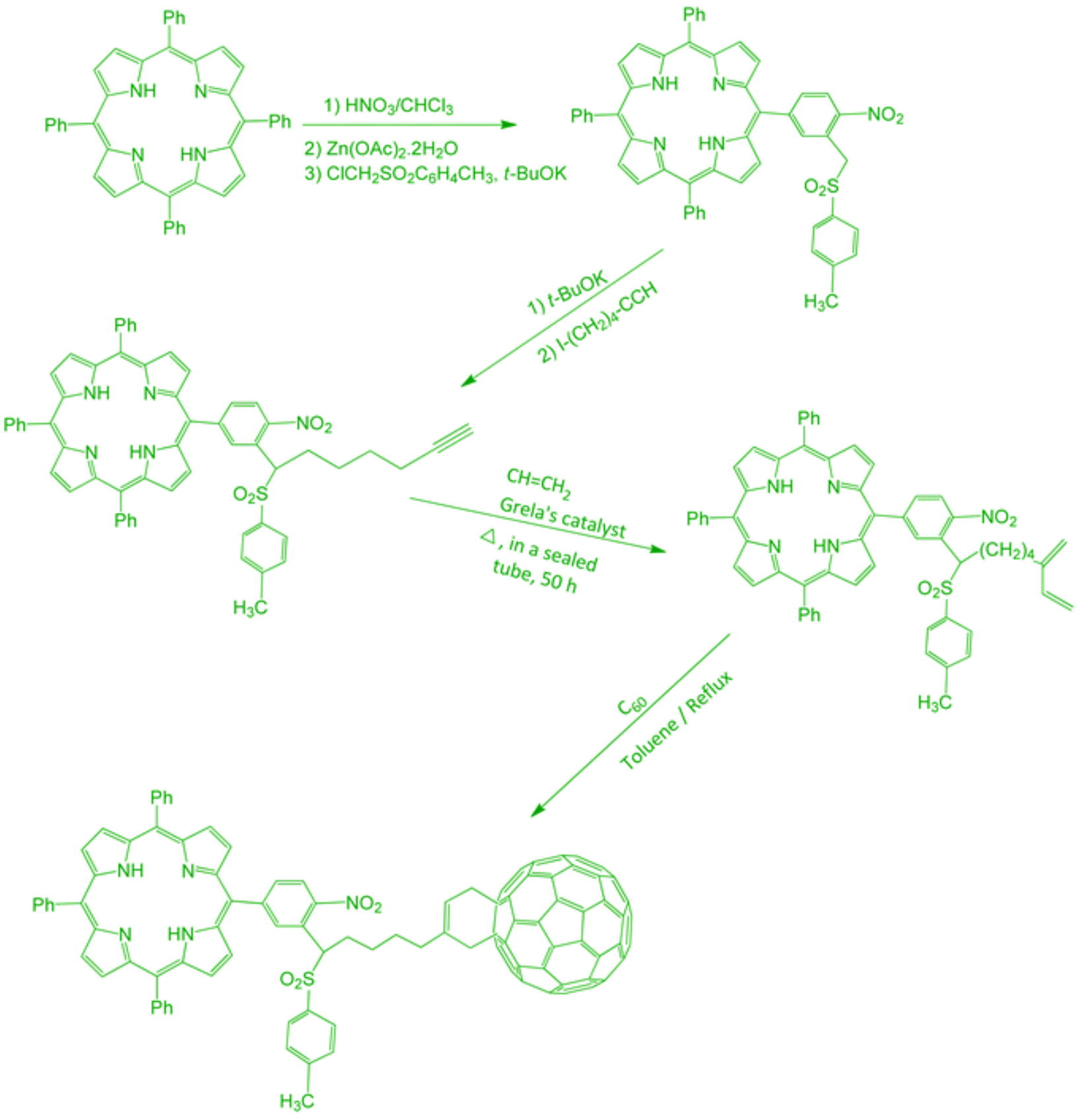

Fig. 11 Reaction showing the [4+2] cycloaddition of a porphyrin onto a fullerene. ${ }^{131}$

The product is alkylated to bear an acetylenic functional group. Rearrangement of the acetylenic group to diene is essential so as to use the latter as the point of attachment to fullerene. The rearrangement mechanism is aided by intermolecular enyne metathesis in the presence of a ruthenium based catalyst. The Diels-Alder cycloaddition reaction is performed by refluxing a porphyrin-fullerene mixture for $5 \mathrm{~h}$ in toluene. The dyad can also be prepared using a shorter spacer that links the terminal acetylenic group to the sulphone substituent on the porphyrin. ${ }^{142}$

Porphyrin-fullerene hybrids can be achieved by utilizing various chemical entities which act as linkers (Fig. 12). These linkers bring the two compounds into close proximity that facilitates spatial interactions between porphyrins and fullerenes, further resulting in hybrid formation by covalent bonding. Several types of surface modifications have been demonstrated to obtain 
glycol-linked, ${ }_{144}$ aza-linked, ${ }^{145}$ catechol-linked, ${ }_{146}^{146}$ naphthalene-linked,,${ }^{147}$ and steroid-

linked ${ }^{148}$ fullerenes; these linkers attach to the chromophore, forming stable covalent hybrids. 


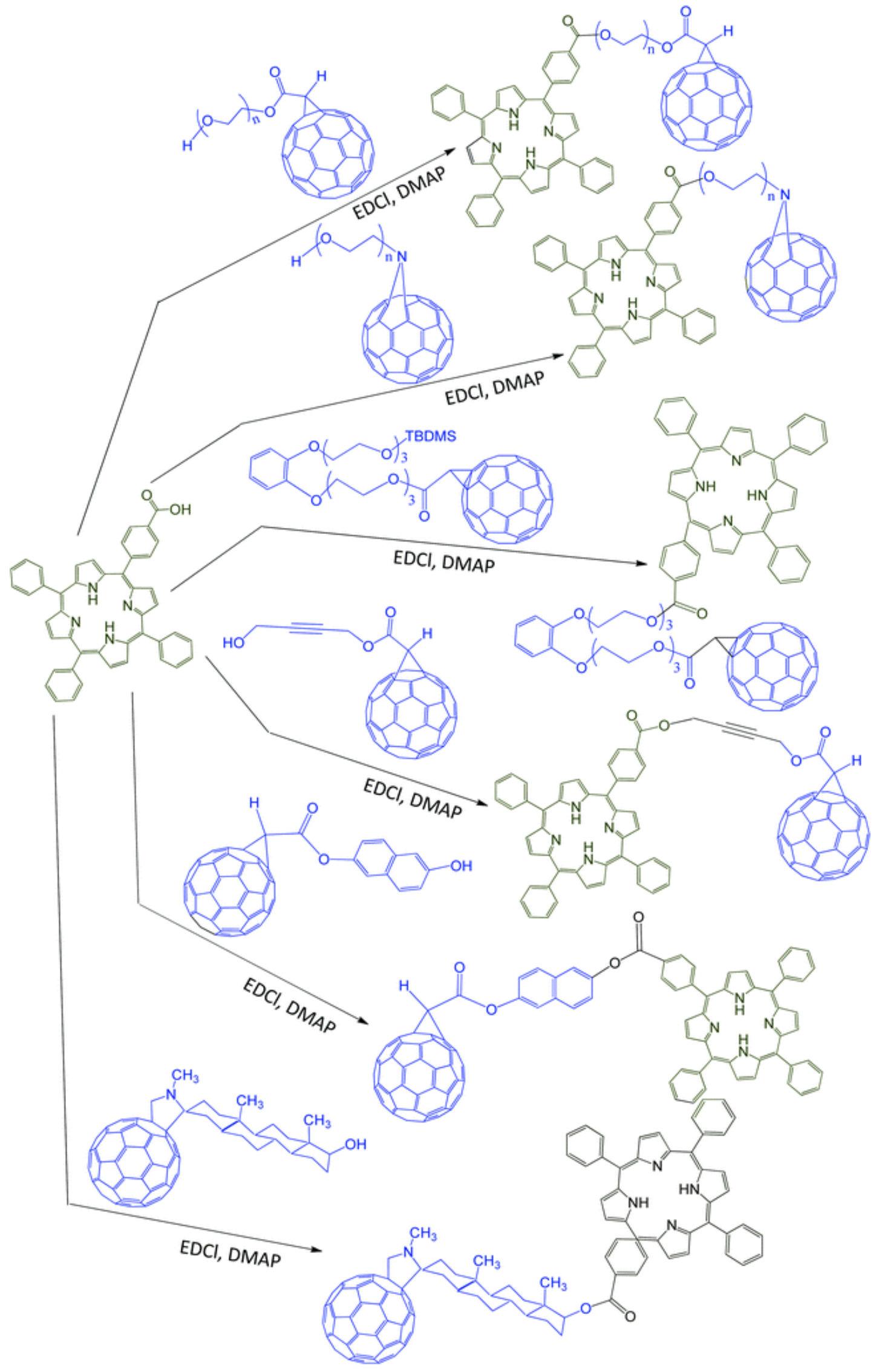


Fig. 12 Immobilization of porphyrins onto fullerenes via various linkages. $\frac{143}{3}$

Gervaldo et al. in 2010 proposed another procedure to functionalize fullerene $\mathrm{C}_{70}$ with porphyrins. ${ }^{149}$ The method involves a reaction between pyridyl group substituted 5-(4formylphenyl)-10,15,20-tris(4-pyridyl)-porphine (D-TMPyP) and $\mathrm{C}_{70}$ in bromobenzene (Fig. 13). Sarcosine added to the reaction mixture facilitates linkage between the two compounds. Conjugation reaction was facilitated by refluxing the solution containing porphyrin and $\mathrm{C}_{70}$ in an argon atmosphere for $1 \mathrm{~h}$ followed by the formation of a porphyrin and fullerene $\mathrm{C}_{70}$ amphiphilic dyad. Sarcosine is also found to assist the conjugation of porphyrins with an aniline substituent and fullerene $\mathrm{C}_{60}$ via the Prato reaction. This intriguing method involves the formation of a dyad, whose polymerization $\frac{150.151}{1}$ causes a hole- and electron-conducting electropolymer. The mesoposition of 5-(4-formylphenyl)-15-(2,4,6-trimethylphenyl)porphyrin is first brominated, followed by its replacement by the 4-aminophenyl group via the Suzuki-type coupling reaction. The hybrid formation occurs through the Prato reaction by mixing $\mathrm{C}_{60}$, sarcosine and porphyrin. The interesting part of this hybrid lies in its polymerization by an electrochemical method where the aminophenyl group attached to the porphyrin forms a linear chain.
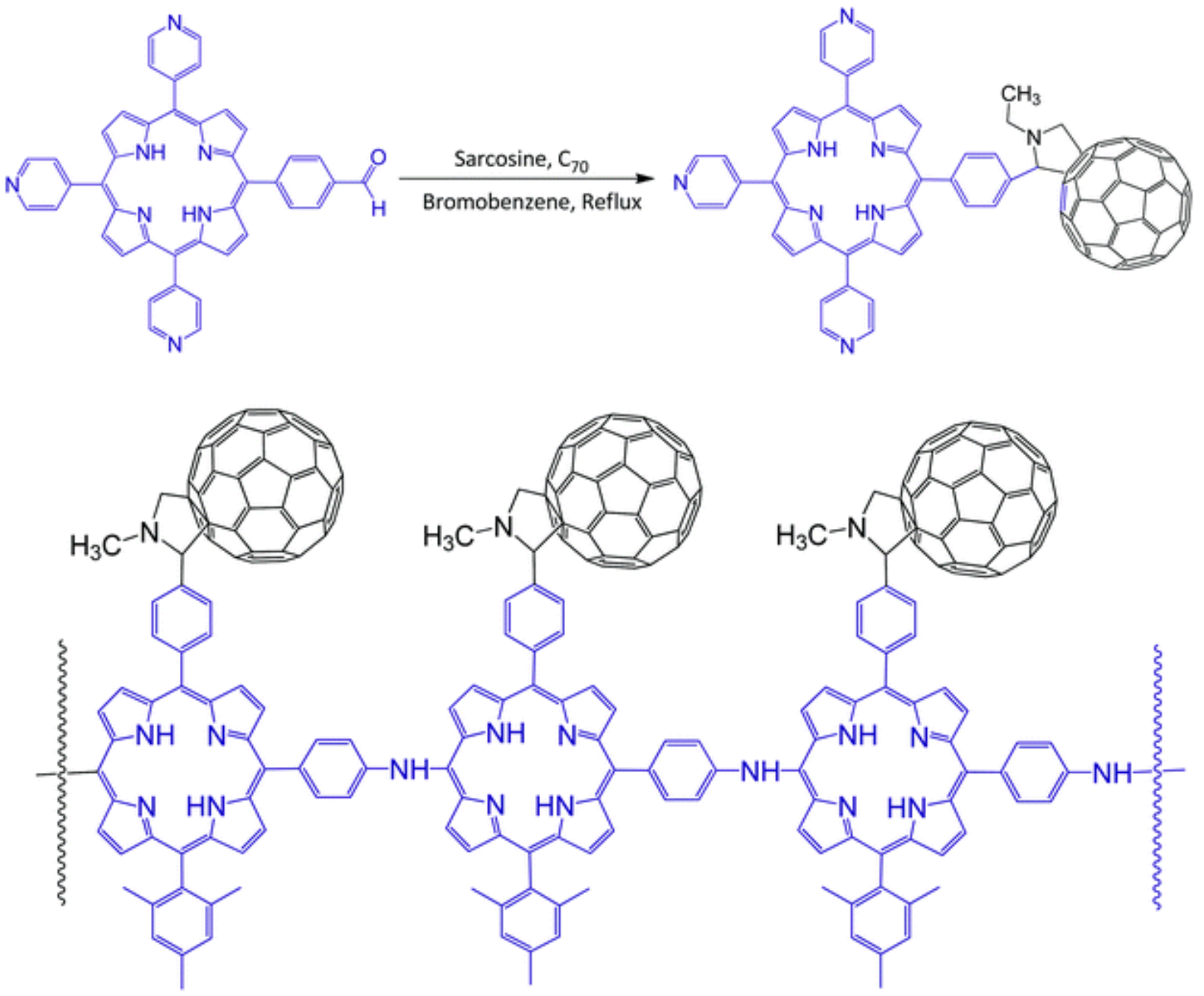

Fig. 13 Formation of a porphyrin-fullerene dyad followed by electropolymerization. $\frac{149}{}$ 
A porphyrin-fullerene hybrid can be prepared in the form of donor-bridge-acceptor molecules. Urbani et al. prepared a conjugate system of triad and tetrad molecules in which one and two porphyrin molecules are immobilized onto fullerene $\mathrm{C}_{60}$, respectively, by covalent linkages through phenylethynyl-oligothienylenevinylene bridges. .152

Researchers have prepared porphyrin-fullerene assemblies by depositing porphyrin molecules on thin films made of fullerenes as shown in Fig. 14. Initially, a thin film of fullerenes is formed via a physical vapour deposition technique (PVD) on a highly-oriented pyrolytic graphite (HOPG) support. 15 meso-Tetraphenylporphine and its $\mathrm{Ni}(\mathrm{II})$ and $\mathrm{Co}(\mathrm{II})$ complexes are then adsorbed onto the fullerene thin film by $2 \mathrm{~min}$ PVD in a vacuum. Porphyrins bearing metal centres form ordered non-covalent structures in comparison with the base.

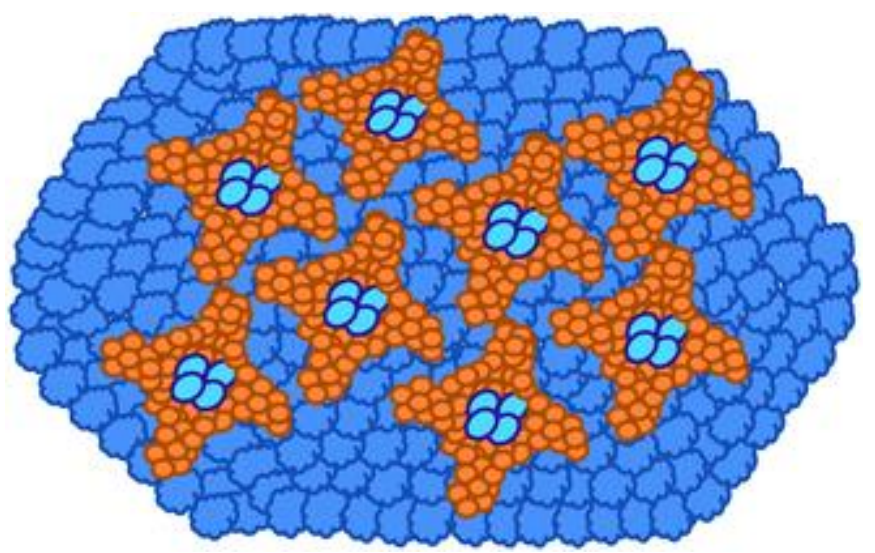

Fig. 14 Porphyrin moieties deposited on a fullerene thin film.

The $\mathrm{C}_{60}$ fullerene is found to have an excellent multi-electron acceptor system with favourable reduction potentials. Due to its minor reorganization energy requirement in electron-transfer reactions, this fullerene can conjugate easily with porphyrins non-covalently ${ }^{154} v i a \pi-\pi$ interactions. In this regard, incorporation of fullerenes into self-assembled porphyrin molecules attracts attention due to a simple procedure involved. In aqueous medium (Fig. 15), $\pi-\pi$ stacking interactions between amphiphilic porphyrin molecules are enhanced by the hydrophobic effect, resulting in their self-assembly. A similar effect is found when a solution of meso-tetrakis-(3,5di-\{2-[2-(2-methoxy-ethoxy)-ethoxy]-ethoxy $\}$-phenyl)-poprhyrin in THF is injected into a pool of water. The assembly in water can be isolated by evaporating the solvent at $80^{\circ} \mathrm{C}$. Fullerene $\mathrm{C}_{60}$ can be introduced into the assembly of porphyrin macromolecules by injecting a mixture of equimolar amounts of the porphyrin and fullerene in toluene followed by THF into water. A noncovalent hybrid of the porphyrin and fullerene $\mathrm{C}_{60}$ is obtained by evaporating the solvent. .155 


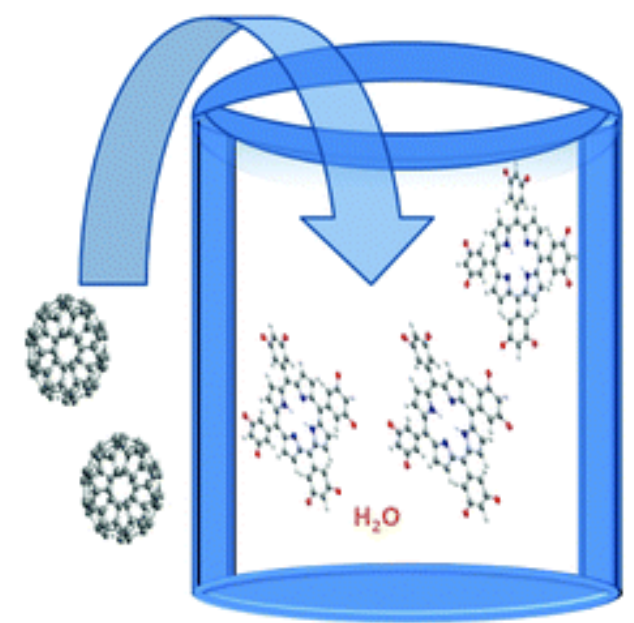

Fig. 15 Porphyrin-fullerene assembly in water. $\frac{155}{15}$

1.3.3 Porphyrin-graphene hybrids. Besides CNTs and fullerenes, graphene is one of the most robust nanoallotropes of carbon. A two-dimensional sheet of hexagonally arranged carbon atoms provides an extended $\pi$-electron system which imparts unique electronic properties to the material. Graphene, being an electron acceptor, can be chemically modified covalently or noncovalently with electron donating organic moieties like porphyrins. $\frac{156,157}{\underline{6}}$

Like in CNTs and fullerenes, the Prato 1,3-dipolar cycloaddition ${ }^{158,159}$ reaction has been proven as an effective method to functionalize graphene with porphyrins. In a stepwise reaction, reduced graphene oxide (RGO) reacts with sarcosine and 4-hydroxybenzaldehyde in DMF at $145{ }^{\circ} \mathrm{C}$ forming OH-functionalized RGO. This is followed by nucleophilic substitution of 5-[4-(2bromoethoxy)phenyl]-10,15,20-triphenylporphyrin (TPP 1), resulting in a RGO-porphyrin covalent nanohybrid. This method requires excess amounts of reactants and also has difficulty in controlling the degree of nucleophilic substitution of $-\mathrm{OH}$ units. A direct Prato reaction can be followed to overcome these disadvantages. A porphyrin containing the formyl group, 5-[4-(2-(4formylphenoxy)ethoxy)phenyl]-10,15,20-triphenylporphyrin, is directly integrated into RGO, in DMF, through the formation of an azomethine ylide (Fig. 16). A similar procedure can also be conducted in $o$-dichlorobenzene instead of DMF at $160^{\circ} \mathrm{C}$. The ylide functionality formed by condensation of the formyl group and $\alpha$-amino acid (sarcosine) acts as a linker in the nanohybrid. .60 


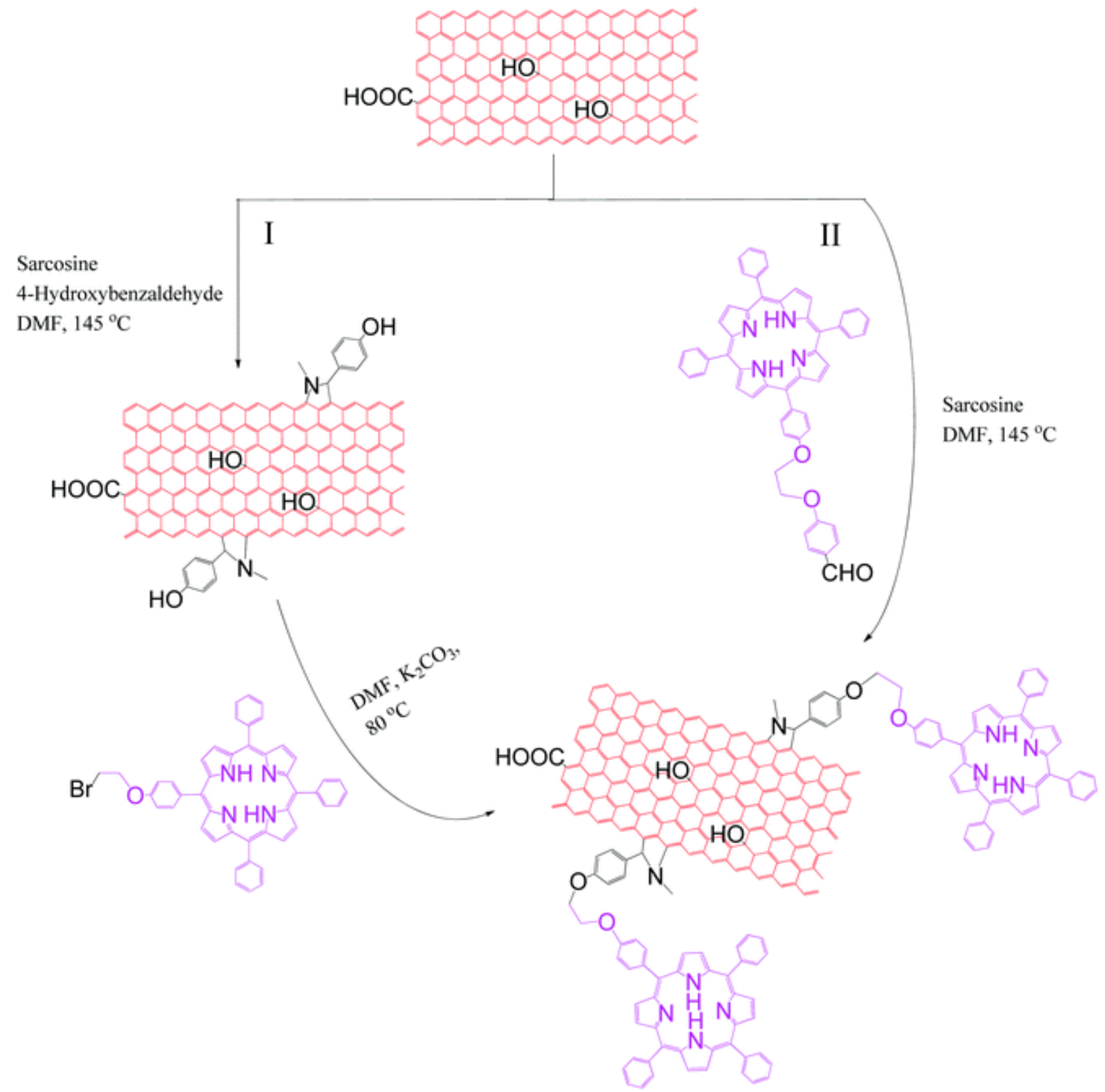

Fig. 16 1,3-Dipolar addition of a porphyrin onto graphene. ${ }^{160}$

Covalent integration of porphyrins onto graphene layers can also be facilitated by amide linkages. A reaction between a porphyrin with the amine group and graphene oxide (GO) results in condensation followed by conjugation of these molecules forming nanohybrids (Fig. 17). The sheet of graphene is converted into graphene oxide that is rich in oxygen containing functionalities obtained by Hummers' method. The derivative obtained by refluxing GO in $\mathrm{SOCl}_{2}$ and $\mathrm{DMF}$ at $70{ }^{\circ} \mathrm{C}$ under an argon atmosphere for 24 hours is allowed to react with 5-(4aminophenyl)-10,15,20-triphenylporphyrin (TPP- $\mathrm{NH}_{2}$ ) in the presence of a base, triethylamine $\left(\mathrm{Et}_{3} \mathrm{~N}\right)$, at $130{ }^{\circ} \mathrm{C}$ for 72 hours under inert conditions. The carboxyl group of $\mathrm{GO}$ and the amine group of TPP undergo condensation reaction forming a TPP-NH-CO-graphene nanohybrid. $\frac{161-166}{16}$ 


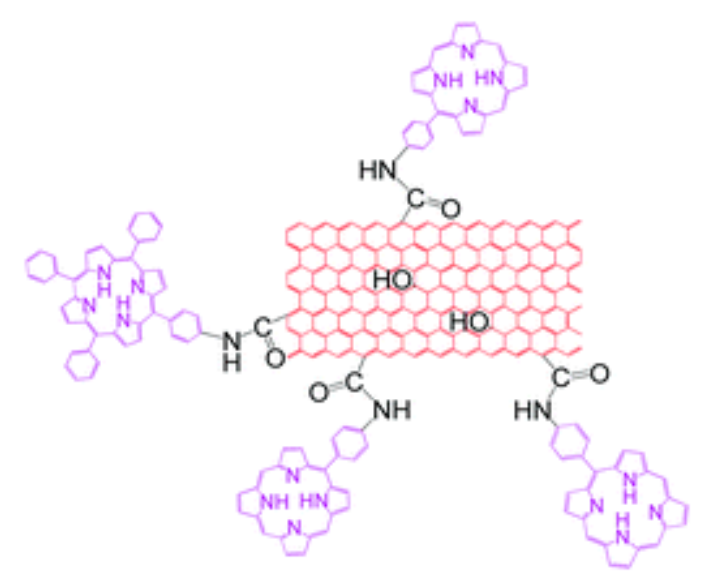

Fig. 17 Covalent conjugation of porphyrin molecules and graphene via amide linkages. .61

Other than these procedures, porphyrins can be conjugated to graphene or to its oxidized/reduced forms by non-covalent means. The structures of the porphyrins are almost planar even with different substituents. The 2D $18 \pi$ electrons of the porphyrins interact easily with the 2D layers of graphene and this can be achieved by a solvothermal method. In one such successful attempt, a mixture of graphene oxide and a porphyrin is added to $\mathrm{N}$-methyl-2pyrrolidone (NMP) and tetrabutylammonium hydroxide (TBA). The mixture is stirred at room temperature but under an argon atmosphere at $800 \mathrm{rpm}$ for seven days. Finally, a $\pi-\pi$ stacked porphyrin-graphene oxide hybrid is isolated from the solvent by centrifugation at $5000 \mathrm{rpm}$ for $30 \mathrm{~min} .167 .168$

The interesting reaction of porphyrins and graphene is also found in thin films. ${ }^{169-171} \mathrm{~A}$ thin film of graphene, in the form of reduced graphene oxide (RGO) cast on glass, is used for this purpose. The film of RGO is immersed into an aqueous solution of a cationic porphyrin, 5,10,15,20tetrakis(1-methyl-4-pyridinio)porphyrin tetra( $p$-toluenesulfonate) (TMPyP), which results in the attachment of the porphyrin onto the RGO film. With increase in immersion time, the interaction between the compounds is found to increase. Moreover, it is also found that higher solution concentration facilitates the faster rate of binding onto the film, resulting in non-covalent hybrids. 172

Non-covalent conjugation of porphyrins and graphene ${ }^{173-175}$ is promoted by different types of interactions, viz., $\pi-\pi$ stacking, van der Waals forces and/or electrostatic attraction or repulsion. When water soluble negatively charged and positively charged porphyrins, 5,10,15,20tetraphenyl-21H,23H-porphine- $p, p^{\prime}, p^{\prime \prime}, p^{\prime \prime \prime}$-tetrasulfonic acid tetrasodium hydrate $\left(\mathrm{TPP}-\mathrm{SO}_{3} \mathrm{Na}\right)$ and 5,10,15,20-tetrakis(4-trimethylammoniophenyl)porphyrin tetra( $p$-toluenesulfonate) (TPPammonium), respectively, are mixed with GO in aqueous medium, they interact via $\pi-\pi$ stacking (Fig. 18). A stability study of the nanohybrids formed reveals that the GO/TPP-ammonium suspension is temporarily stable, resulting in precipitation upon storage; whereas $\mathrm{TPP}-\mathrm{SO}_{3} \mathrm{Na}$ enhances the dispersion of GO in water. The negatively charged TPP-SO${ }_{3} \mathrm{Na}$ moieties aggregated on the GO surface do not allow close interaction between GO sheets due to anionic electrostatic repulsion, thereby increasing the stability of the suspension. ${ }^{176}$ 


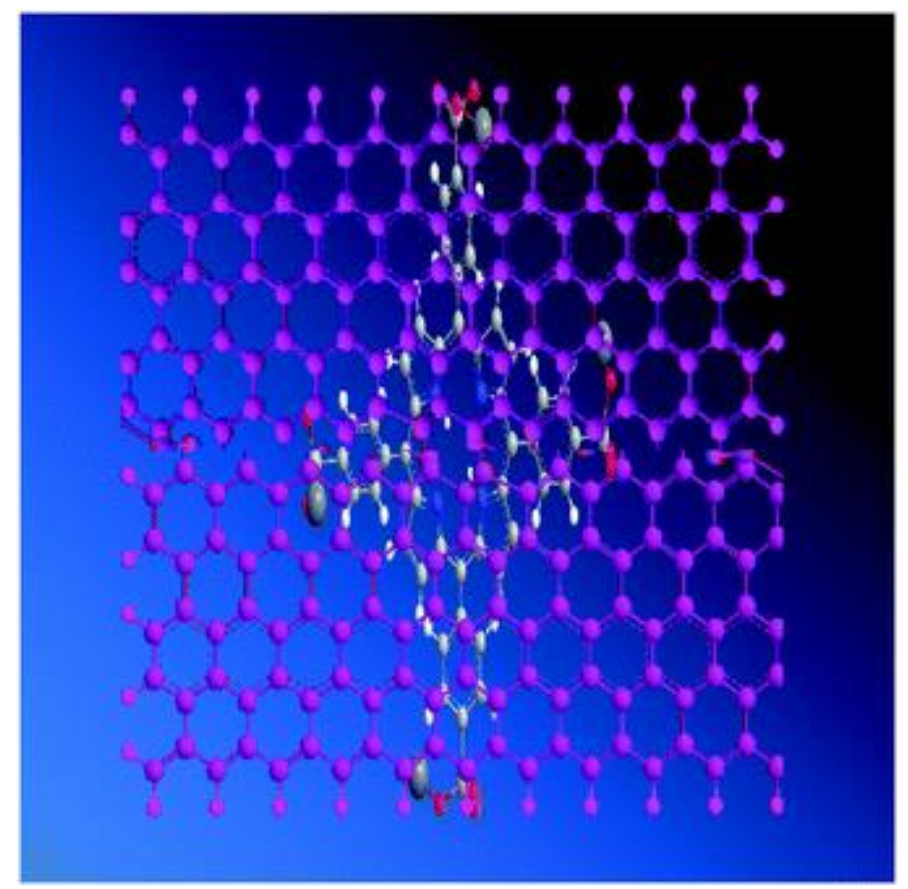

Fig. 18 Schematic representation of porphyrin trapping on a graphene layer. $\frac{177.178}{1}$

1.3.4 Porphyrin-carbon nanohorn hybrids. The beauty of carbon nanomaterials is that they can be synthesized in various shapes and morphologies and thus exhibit attractive properties. Besides tubular, ball like and layered structures, carbon can also be derived in the form of nanohorns. $\frac{179.180}{}$ These high purity carbon nanostructures obtained by disintegration of graphite (hence no metal impurities) provide an excellent platform to produce tailored assemblies with porphyrins. Extensive work done in this area has revealed many covalent and non-covalent ways to conjugate porphyrins and carbon nanohorns, thereby producing stable nanohybrids. $\frac{181-184}{11}$

To obtain stable covalent hybrids of carbon nanohorns (CNHs) and porphyrins, $\mathrm{CNH}$ surfaces can be initially modified with different easily tunable substituents that can form bonds with porphyrins. One such functionality on $\mathrm{CNH}$ that favours bond formation is the amino group. A free-base porphyrin with tetracarboxylic acids $\left(\mathrm{H}_{2} \mathrm{P}\left(\mathrm{CO}_{2} \mathrm{H}\right)_{4}\right)$ is found to conjugate with amino $\mathrm{CNH}$ both covalently and non-covalently in aqueous medium. Covalent conjugation occurs through the formation of amide linkages (Fig. 19), ${ }^{185.186}$ whereas non-covalent interaction occurs through $\pi-\pi$ stacking and effective ionic bonding..$^{187.188}$ 


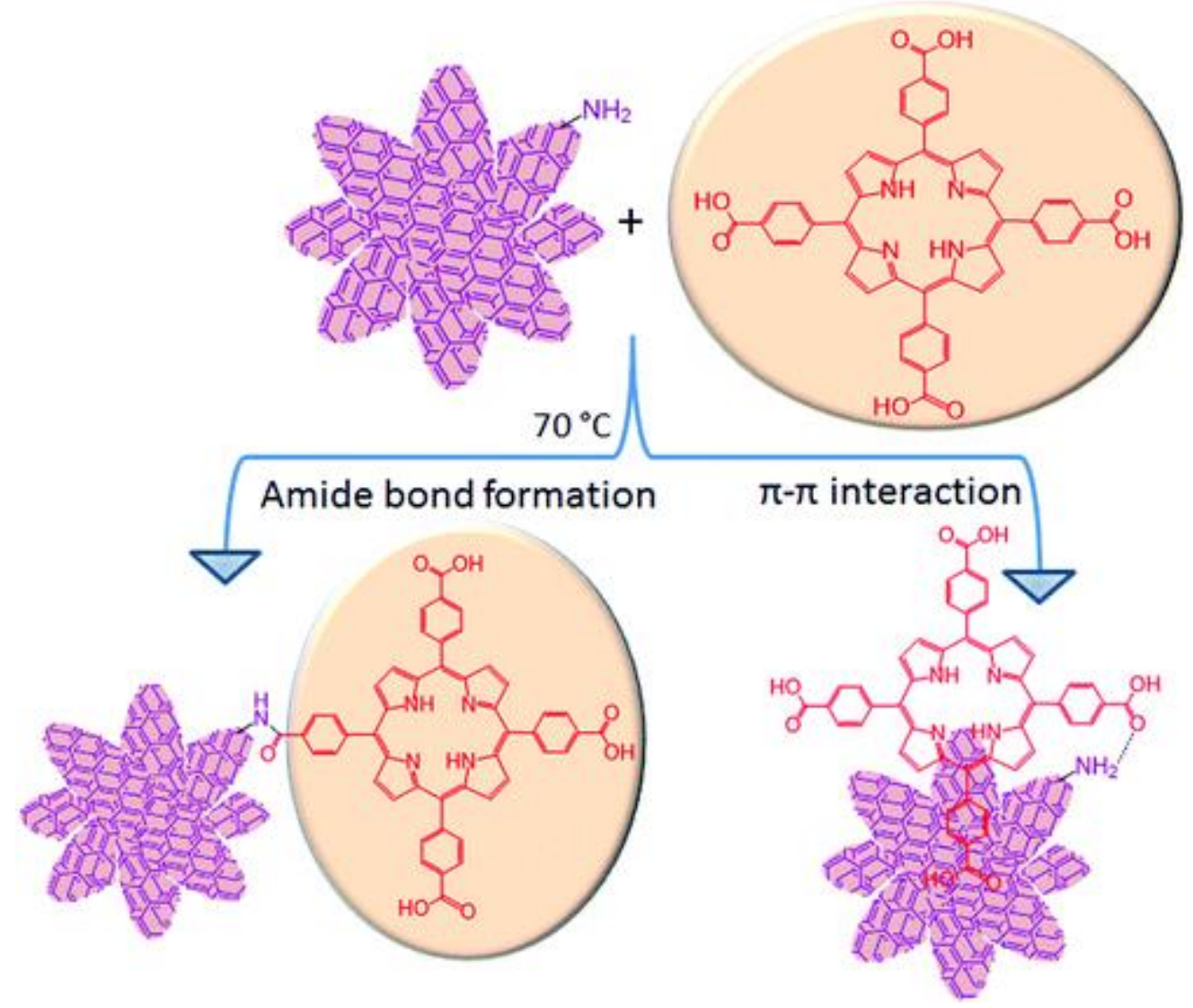

Fig. 19 Covalent and non-covalent nanohybrid formation between a porphyrin and a carbon nanohorn. ${ }^{185}$

CNHs are excellent electron acceptors and possess the ability to diffuse the electrons readily along the cone axis with negligible loss of energy. This inspires the formation of electron donoracceptor nanohybrids of CNHs and porphyrins (Fig. 20). In this regard, amide linkages have proven to be one of the suitable pathways to synthesise these nanohybrids. One such attempt made by mixing an amino-group possessing porphyrin, $\alpha-5$-(2-aminophenyl)- $\alpha-15-(2-$ nitrophenyl)-10,20-bis(2,4,6-trimethyl-phenyl)-porphyrin, and carboxylic acid bearing $\mathrm{CNH}$ produces a stable nanohybrid in organic solvents such as THF and dichloromethane. The pristine CNHs are initially modified to obtain carboxylic group functionalities at the surface by heating at $580{ }^{\circ} \mathrm{C}$. These carboxylic groups are utilized to form amide linkages with porphyrins in later stages. $\frac{189.190}{10}$ 


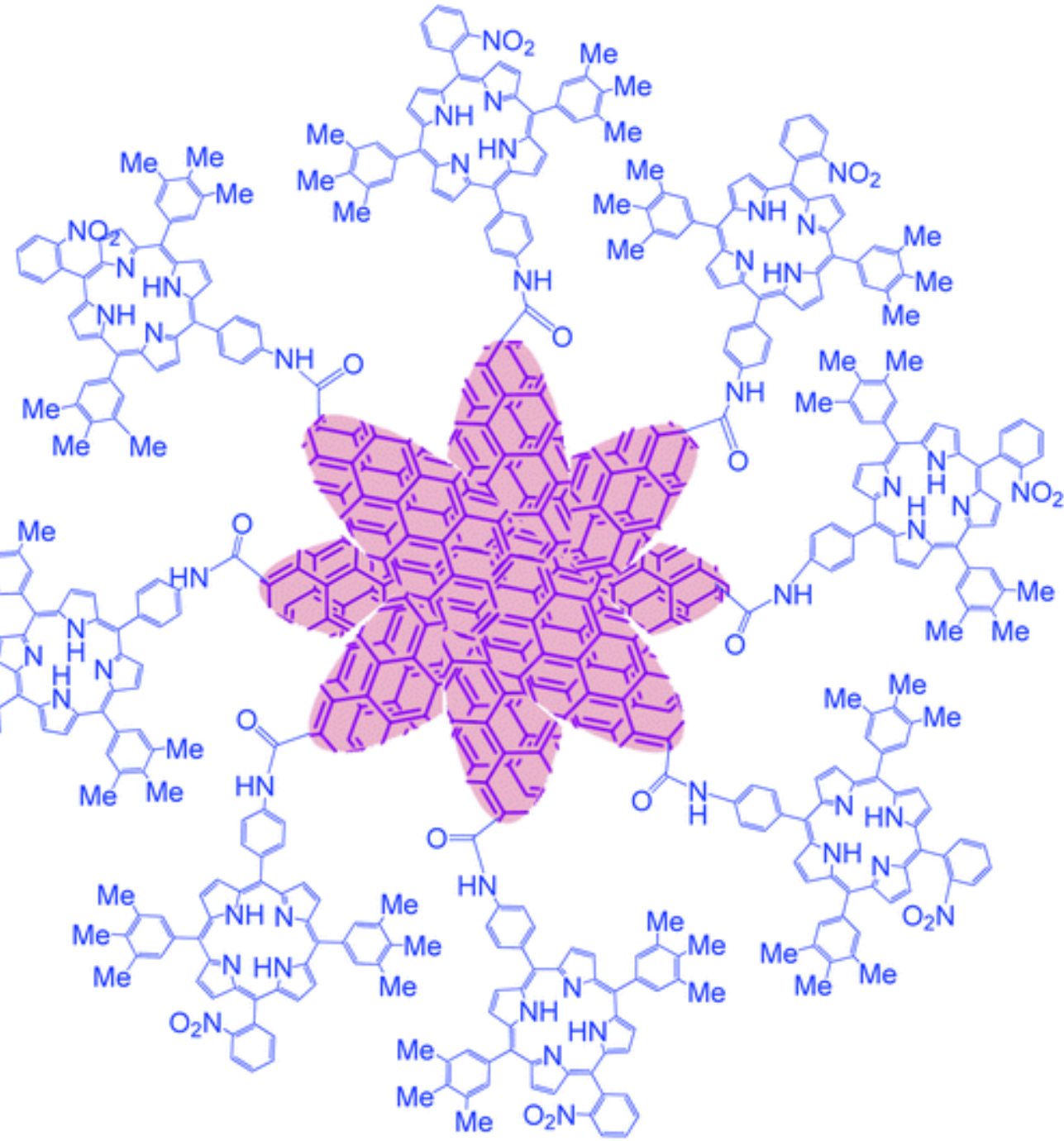

Fig. 20 Schematic of porphyrin-CNH hybrids. ${ }^{18}$

Covalent conjugation of porphyrins onto $\mathrm{CNH}$ s takes place on graphitic side walls or at the conical tip. In covalent linkages, there will be perturbation of the continuous $\pi$ electronic system of CNHs that leads to an enhanced dispersion of the functionalised material and solubilisation. This issue can be overcome by supramolecular approaches by utilizing secondary interactions such as $\pi-\pi$ stackings between the $\mathrm{CNH}$ sidewalls and porphyrin molecules. This can be brought about by modifying the surfaces of the $\mathrm{CNH}$. In such research work, the pristine $\mathrm{CNH}-\mathrm{COOH}$ is treated with tert-butyl- $N$-(6-aminohexyl)carbamate in DMF followed by treatment with $\mathrm{HCl} /$ dioxane that results in $\mathrm{CNH}$-spacer (sp)- $\mathrm{NH}_{3}{ }^{+}$. The $\mathrm{CNHs}$ covalently attached to the ammonium cations through the spacer are rich in the amide group, the ethylene spacer and $\mathrm{NH}_{3}{ }^{+}$and are used as substrates to form a supramolecular assembly with a zinc porphyrin linked to a crown ether (crown- $\mathrm{ZnP}$ ). CNH-sp- $\mathrm{NH}_{3}{ }^{+}$and crown- $\mathrm{ZnP}$ are mixed in $\mathrm{DMF}$ at room temperature followed by stirring for $2 \mathrm{~min}$. During the stirring process, the two compounds are brought into close proximity, resulting in interaction between the $\mathrm{CNH}$ and porphyrin producing a stable nanohybrid. ${ }^{189}$

Non-covalent conjugation between CNHs and porphyrins can also be brought about in aqueous medium using water soluble porphyrins. $\{5,10,15,20$-Tetrakis-(1-methyl-4- 
pyridinio)porphine tetra-( $p$-toluenesulfonate) $\}$ gets immobilized onto $\mathrm{CNH}$ sidewalls by mild sonication for a very short period, $3 \mathrm{~min}$ in aqueous solution. The mixture is stirred vigorously for 20 hours that brings interactions between the two entities. The black non-covalent hybrid of the $\mathrm{CNH}$ and porphyrin formed is isolated by centrifugation after removing any unbound porphyrin by decantation. $\frac{181}{1}$

Researchers have been working on various possibilities to design supramolecular assemblies between porphyrins containing a range of metal centres and substituent groups and CNHs. In this regard, use of metal oxides as bridges between porphyrins and CNHs has attracted attention due to the synergistic effect exhibited by the resulting nanohybrid. Tu et al. ${ }^{191}$ has reported a supramolecular assembly, where titanium oxide acts as bridge between metalloporphyirns and CNHs. Here, the carboxylate groups present on ferriprotoporphyrin and CNHs attach onto titanium oxide $\left(\mathrm{TiO}_{2}\right)$ nanopaticles' surface via dentate binding. The metal bridged porphyrin$\mathrm{CNH}$ hybrid is found to have enhanced electrocatalytic activity.

\section{Applications}

CNAs have made a revolution in the fields of nanoscience and nanotechnology due to their excellent structural, optical, mechanical and electronic properties - thanks to their huge surface area and chemical stability, which make their application ubiquitous over a wide range of fields. Yet, their chemical inertness, insolubility in organic matrices and tendency to form aggregates hinder their use. With respect to this, the enhancement of nanocarbon surfaces by functionalization with porphyrins results in increased dispersion quality and solubility. The immobilization of porphyrins onto nanocarbon surfaces can be achieved via either covalent or non-covalent interactions. The nanohybrids thus formed exhibit optimized properties compared to the pristine compounds and thus effectively contribute to various fields of applications.

\subsection{Porphyrin-CNM hybrids in catalysis}

Porphyrin/nanocarbon hybrids are gaining worldwide attention due to their excellent catalytic performances. Their ability to convert raw materials into valuable products even when reused has made them useful for commercial applications.

Metalloporphyrins supported on carbon nanoallotropes build stable, heterogeneous catalysts that can be easily separated from the reaction system. Metalloporphyrin functionalised CNTs proved to be promising catalysts in the oxidation of alkenes to epoxides using hydrogen peroxide $\left(\mathrm{H}_{2} \mathrm{O}_{2}\right)$ as an oxidant. The catalytic efficiencies of the nanohybrids are found to increase in protic solvents and with irradiation using ultrasonic waves. When the bubbles formed during sonication explode, they produce an enormous amount of energy that facilitates the reaction to complete in a shorter duration.

The proposed catalytic mechanism (Fig. 21) explains the initial coordination of $\mathrm{H}_{2} \mathrm{O}_{2}$ to the metal centre of the porphyrin, forming a penta-coordinated intermediate that can sometimes generate an iron-oxo intermediate. In the later step, the olefin attacks as a nucleophile at the oxygen atom of coordinated $\mathrm{H}_{2} \mathrm{O}_{2}$ or iron-oxo intermediate forming an epoxide product. Similar reactions can be carried out using molecular oxygen as an oxidant to oxidize olefins and various sulfides such as methyl phenyl sulfide, diphenyl sulfide, benzyl phenyl sulfide, phenyl vinyl sulfide and 4-chlorophenyl methyl sulfide via a free radical reaction mechanism. ${ }^{192.193}$ 


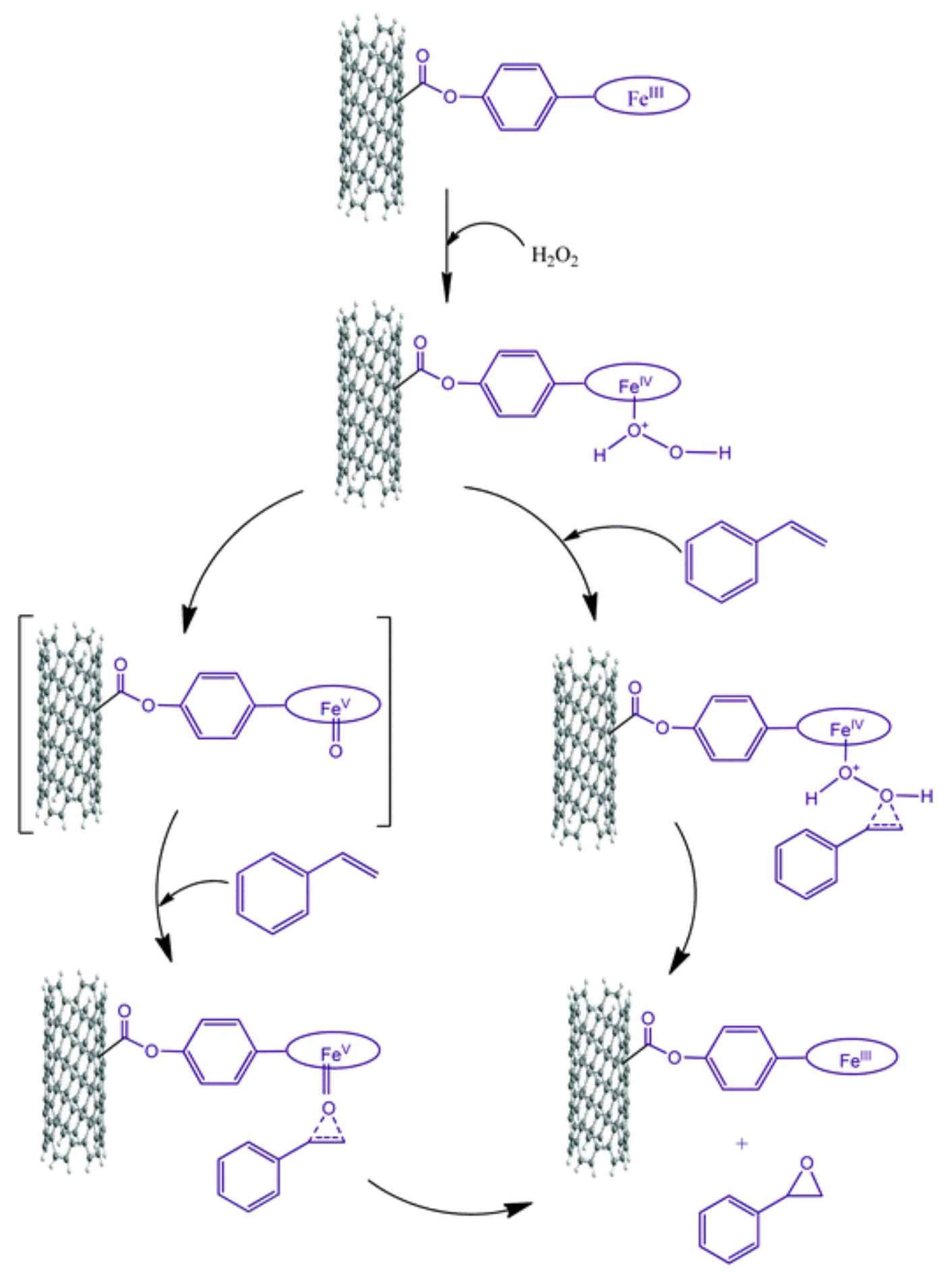

Fig. 21 Proposed catalytic mechanism exhibited by a porphyrin-CNT hybrid. ${ }^{192}$

Porphyrin/carbon nanomaterial hybrids also catalyse hydrogenation reactions such as transformation of levulinic esters into heterocyclic compounds such as $\gamma$-valerolactone and pyrrolidone derivatives. A polymer of a ruthenium porphyrin supported on CNTs via $\pi-\pi$ stacking is an excellent heterogeneous catalyst which shows a conversion efficiency of more than $99 \%$. Like CNTs, graphene and graphene oxides are also found to support porphyrin 
catalysts that convert esters to $\gamma$-valerolactone and pyrrolidone with similar conversion capacities. $\frac{194}{}$

The hybrids are capable of eliminating pollutants from the environment by playing the role of catalysts in their oxidative decomposition. ${ }^{105.196}$ Mercaptans are one class of such toxic and corrosive gaseous compounds, hazardous to the environment. Porphyrins supported on CNTs are efficient catalysts to remove mercaptans from a gas stream by an oxidation reaction. ${ }^{197}$ The reaction is accompanied by conversion of mercaptan to disulfide in the presence of potassium hydroxide.

Porphyrin/carbon nanomaterial hybrids also catalyse the oxygen reduction reaction through electrochemical activities. These electrocatalysts possess high electrochemically accessible surface area, stability and tolerance to the methanol crossover effect in the reduction reaction. Moreover, these hybrid catalysts enable a direct four electron pathway to reduce oxygen in alkaline medium. Because of their outstanding catalytic performance, porphyrin/nanocarbon hybrids replace high cost metallic catalysts such as platinum, ruthenium complexes, etc. ${ }^{198-203}$

$$
2 \mathrm{RSH}+1 / 2 \mathrm{O}_{2} \underset{\text { Poophyrin-CNT hybrid catalys }}{\longrightarrow} \mathrm{RS}-\mathrm{SR}+\mathrm{H}_{2} \mathrm{O}
$$

The hybrids also perform electroreduction of carbon dioxide $\left(\mathrm{CO}_{2}\right)$. The resistance at the electrode interface greatly decreases due to the high surface area and excellent electrical conductivity of the CNTs, which allow easy movement of electrons between the porphyrins and CNTs. As a result, the potential for $\mathrm{CO}_{2}$ reductions decreases, resulting in an increased reaction rate. .04 In a similar way, porphyrin-CNT hybrids cause the oxidation of nitric oxide. The mechanism is attributed to the fast transfer of electrons through axial coordination of CNTs and porphyrins. .205

\subsection{Porphyrin-CNM hybrid based sensors}

In recent years, porphyrin immobilized carbon nanomaterials have also been used as sensors. Porphyrin-CNM hybrids can be used as sensors due to their extended catalytic efficiencies as many detection procedures seek catalytic redox reactions. 206 These sensors are cost effective and easy to use and exhibit rapid and sensitive response. An anionic porphyrin, meso-tetra(4carboxyphenyl)porphine (TCPP), supported on a chemically converted graphene (CCG) is selective in the detection of dopamine by an electrochemical method. During this phenomenon, the hybrid interacts with positively charged dopamine via $\pi-\pi$ stackings and electrostatic attraction, thus resulting in higher redox current compared to a bare electrode. The higher redox peak indicates the presence of dopamine and hence the hybrid can be used to detect dopamine ${ }^{207,208}$ in various samples like hydrochloride injections, human serum and urine samples.

An iron-porphyrin ([3,7,12,17-tetramethyl-8,13-divinylporphyrin-2,18dipropanoato(2-)]iron(III)) functionalised multi-walled carbon nanotube is found to be capable of determining ascorbic acid, dopamine, uric acid and nitrite, which if present in abnormal levels indicate many disorders such as infertility, Huntington's disease, leukaemia, dopamine levels, and many more respectively. The metallic centre in the porphyrin can undergo rapid electron transfer, resulting in a reversible redox potential of $\mathrm{Fe}^{3+} / \mathrm{Fe}^{2+}$. This mechanism promotes the preparation of desirable sensors based on porphyrin/nanocarbon conjugates. ${ }^{209}$

Porphyrin-CCG hybrids produce electrocatalytically active and electrochemically stable sensor systems to detect oxygen and hydrogen peroxide in solution. $\frac{210}{}$ With similar electrochemical procedures, porphyrins-GO hybrids can be used as sensors to detect serotonin. Further, a biosensor can also be created out of porphyrin-CNM (graphene quantum dot) 
hybrids ${ }^{211-214}$ to detect glucose via a fluorescence method as the hybrid exhibits good fluorescence properties.

One of the major utilization of porphyrin-CNM hybrids is found in the detection of ultratraces of explosives. Explosives are generally made of aromatic nitro compounds. Therefore, the material used to sense and electrochemically detect these compounds should exhibit excellent adsorption capacities. Porphyrin immobilized graphene, due to its high conductivity, chemical and mechanical stability, huge surface-to-volume ratio and easy charge transfer, facilitates the adsorption of explosive compounds.

Different explosive nitro compounds such as 2,4-dinitrotoluene, 2,4,6-trinitrotoluene, 1,3,5trinitrobenzene and 1,3-dinitrobenzene are identified by the hybrid sensor based on two reduction peaks obtained using electrochemical studies. Out of the two peaks, one corresponds to the reduction of the nitro group to hydroxylamine, which is followed by the reduction of the latter to the amine group. $\frac{212}{2}$ The mechanism is shown in Fig. 22.

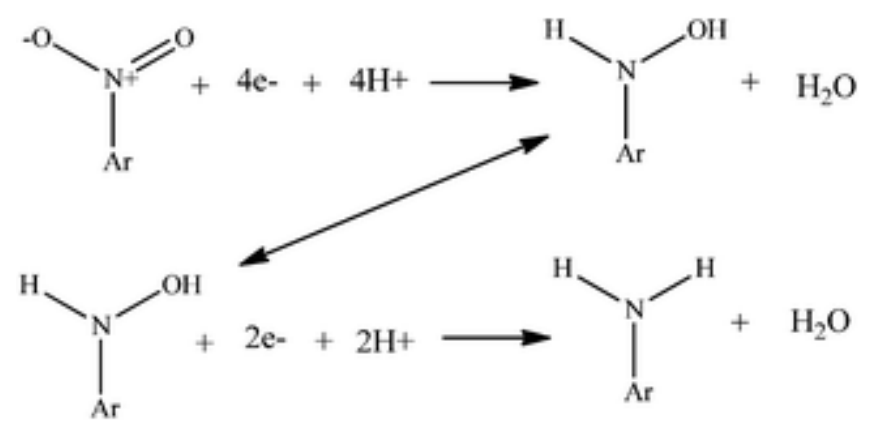

Fig. 22 Scheme showing the electrochemical reduction of the nitro group in an explosive nitroaromatic compou

The porphyrin-carbon nanomaterial hybrids have also proven their efficiency as sensors to detect volatile organic compounds. They work based on a combined effect of electrostatic gating and Schottky barrier modulation. The electrical responses collected are compared with the pattern-recognition analysis tool for the selectivities and sensitivities of the sensors. $16-219$

\subsection{Porphyrin-CNM hybrids in photovoltaics}

Porphyrins have emerged as suitable materials for photovoltaic applications due to their high extinction coefficients and photostability. They imitate natural photosynthesis to carry out photovoltaic processes by harvesting light and separation and transport of charges.220 The hybrids of porphyrins and carbon nanoallotropes provide wonderful electron donor-acceptor ${ }^{221}$ systems, with carbon nanoallotropes being electron acceptors, which help in envisioning more advanced photovoltaics. ${ }_{222}$ Upon photoillumination, charge separation (cs) takes place (Fig. 23) in the nanohybrid forming two ephemeral radical ion species such as porphyrin ${ }^{+}\left(\mathrm{H}_{2} \mathrm{P}^{\cdot+}\right.$, where $\mathrm{H}$ can be replaced by a metal atom) and $\mathrm{CNM}^{-}{ }^{-}$. The negative value of $\Delta G_{\mathrm{cs}}$ demonstrates that the charge separation in a porphyrin-CNM hybrid is a thermodynamically favourable process. 223 The significant number of electrons released during the process can be pooled using an electron mediating agent, like hexyl viologen $\left(\mathrm{HV}^{2+}\right)$, and a hole shift agent like 1-benzyl-1,4dihydronicotinamide (BNAH). The mediation of electrons from the hybrid to $\mathrm{HV}^{2+}$ causes $\mathrm{HV}^{\cdot}$, creating holes in the hybrid. During this process, the concentration of $\mathrm{HV}^{\cdot}+$ increases with increasing quantity of BNAH; as a result, the hole from the hybrid shifts to BNAH, forming $\mathrm{BNA}^{+}$. These electrons and holes are favourable in photovoltaics. ${ }^{224}$ 


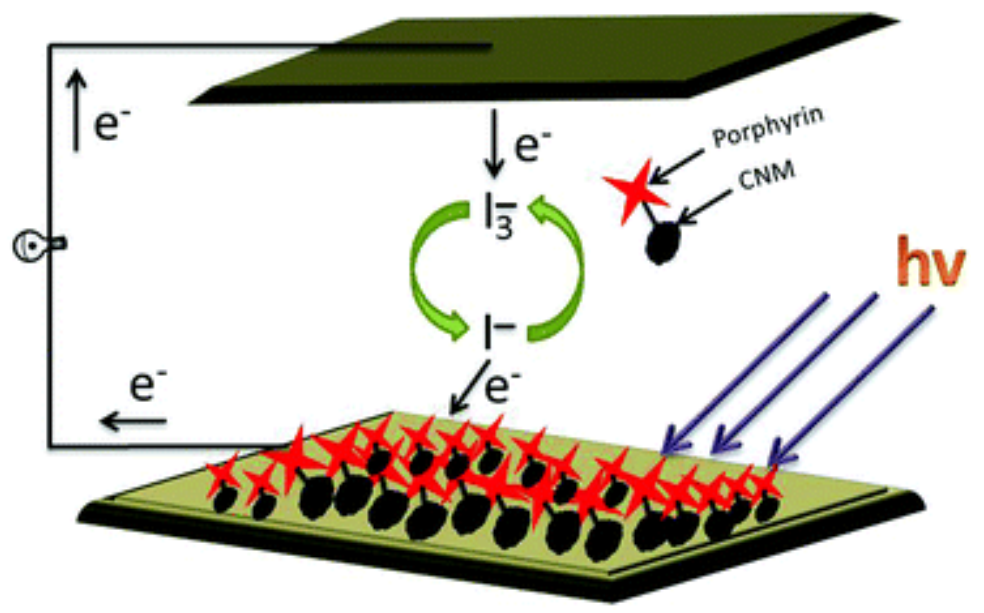

Fig. 23 Pictorial representation of electron transfer in a porphyrin-CNT hybrid photovoltaic cell. 217

\section{Future direction}

The structural, physical, mechanical, optical and electronic properties of carbon nanomaterials such as carbon nanotubes, fullerenes, graphenes and nanohorns are favourable to obtain supramolecular assemblies with photosensitive porphyrin molecules. The conglomeration of porphyrins and spherical shaped carbon nanoparticles is a less explored territory and the results obtained with porphyrin-CNA hybrids are encouraging for researchers to explore this area. Carbon nanospheres (CNSs) exhibit similar properties to their allotropic carbon nanomaterials and also have smooth surface morphologies. The property that stands as an advantage to CNSs is their porosity, using which they can hold their counterparts strongly, forming stable structures.

CNSs can be produced by a simple and easy method like pyrolysis under controlled conditions. ${ }^{225-230}$ The synthesis of CNSs from bio-waste materials is an attractive proposition and can be envisioned as a scalable "waste to wealth" approach which will have a strong societal impact. We believe that porphyrin-CNS hybrids will find an array of applications in fields like waste water purification, cleansing technology, etc. The synthesis and exploration of such novel porphyrin-carbon nanospheres are currently underway in our laboratory.

\section{Conclusion}

This review summarizes the attractive properties of porphyrins and CNAs as individual compounds and also the optimized characteristics when these two fascinating entities are brought together by chemical means. There are many covalent and non-covalent approaches available to make such hybrid entities. The thermal and chemical stabilities of the hybrids obtained via covalent approaches like click chemistry, 1,3-dipolar cycloaddition, and ester and amide formation supersede the ones produced using non-covalent approaches like electrostatic attractions, $\pi-\pi$ stacking, and polymer wrapping of photosensitizers on CNAs, etc. This article has also critically listed various applications of porphyrin-CNM hybrids in catalysis, sensors, photovoltaics, biotechnology and water treatment. We are optimistic that this article will further stimulate research and enrich the area of porphyrin-CNA hybrids.

\section{Conflicts of interest}

There are no conflicts to declare. 


\section{References}

1. Seidel, R. W.; Oppel, I. M., 1D and 2D solid-state metallosupramolecular arrays of freebase 5,10,15,20-tetra(4-pyridyl)porphyrin, peripherally linked by zinc and manganese ions. Structural Chemistry 2009, 20 (1), 121-128.

2. Seidel, R. W.; Oppel, I. M., 2D Metallosupramolecular Arrays of Zinc-5,10,15,20-tetra(4pyridyl)porphyrin via Self-complementary Coordination and Peripheral Linkage. Zeitschrift Fur Anorganische Und Allgemeine Chemie 2010, 636 (3-4), 446-448.

3. Han, C.; Shao, Q.; Liu, M.; Ge, S. S.; Liu, Q. Y.; Lei, J., 5,10,15,20-tetrakis(4chlorophenyl)porphyrin decorated $\mathrm{TiO} 2$ nanotube arrays: Composite photoelectrodes for visible photocurrent generation and simultaneous degradation of organic pollutant. Materials Science in Semiconductor Processing 2016, 56, 166-173.

4. $\quad$ Li, A.; Zhao, L. Z.; Hao, J.; Ma, R. J.; An, Y. L.; Shi, L. Q., Aggregation Behavior of the Template-Removed 5,10,15,20-Tetrakis(4-sulfonatophenyl)porphyrin Chiral Array Directed by Poly(ethylene glycol)-block-poly(L-lysine). Langmuir 2014, 30 (16), 4797-4805.

5. $\quad$ Wang, R. B.; Brugh, A. M.; Rawson, J.; Therien, M. J.; Forbes, M. D. E., Alkyne-Bridged Multi[Copper(II) Porphyrin] Structures: Nuances of Orbital Symmetry in Long-Range, Through-Bond Mediated, Isotropic Spin Exchange Interactions. Journal of the American Chemical Society 2017, 139 (29), 9759-9762.

6. $\quad$ Li, Z. Z.; Sinha, S.; Treich, G. M.; Wang, Y. F.; Yang, Q. W.; Deshmukh, A.; Sotzing, G. A.; Cao, Y., All-organic flexible fabric antenna for wearable electronics. Journal of Materials Chemistry $C$ 2020, 8 (17), 5662-5667.

7. Ogawa, T., Analysis of Single Molecule Conductance of Heterogeneous Porphyrin Arrays by Partial Transmission Probabilities. Chemistryselect 2017, 2 (25), 7483-7483.

8. Tamaki, T.; Ohto, T.; Yamada, R.; Tada, H.; Ogawa, T., Analysis of Single Molecule Conductance of Heterogeneous Porphyrin Arrays by Partial Transmission Probabilities. Chemistryselect 2017, 2 (25), 7484-7488.

9. $\quad$ Leng, X. B.; Choi, C. F.; Lo, P. C.; Ng, D. K. P., Assembling a mixed phthalocyanine-porphyrin array in aqueous media through host-guest interactions. Organic Letters 2007, 9 (2), 231-234.

10. Gehrold, A. C.; Bruhn, T.; Bringmann, G., Axial, Helical, and Planar Chirality in Directly Linked Basket-Handle Porphyrin Arrays. Journal of Organic Chemistry 2016, 81 (3), 1075-1088.

11. Mulay, S. V.; Bogoslavky, B.; Galanti, I.; Galunc, E.; Gidron, O., Bifuran-imide: a stable furan building unit for organic electronics. Journal of Materials Chemistry C 2018, 6 (44), 11951-11955.

12. Zhang, J. X.; Wu, Y.; Liu, J. C.; Li, R. Z., Bilayer structured supramolecular light harvesting arrays based on zinc porphyrin coordination polymers for enhanced photocurrent generation in dye sensitized solar cells. Dalton Transactions 2016, 45 (41), 16283-16289.

13. Gamage, P.; Fiedler, A.; Stefan, M.; Biewer, M., Bipyrimidine based donor-acceptor conjugated polymers for organic electronics. Abstracts of Papers of the American Chemical Society 2018, 256.

14. Kuklin, S. A.; Konstantinov, I. O.; Peregudov, A. S.; Ostapov, I. E.; Makhaeva, E. E.; Khokhlov, A. R.; Keshtov, M. L., Bis[1,3]thiazolo[4,5-f:5',4'-h]thieno[3,4-b]quinoxaline Derivatives as New Building Blocks of Polymers for Organic Electronics. Doklady Chemistry 2018, 482, 207-211. 15. Zhang, X. N.; Wang, B. H.; Huang, L. Z.; Huang, W.; Wang, Z.; Zhu, W. G.; Chen, Y.; Mao, Y. L.; Facchetti, A.; Marks, T. J., Breath figure-derived porous semiconducting films for organic electronics. Science Advances 2020, 6 (13).

16. Franzke, Y. J.; Sundholm, D.; Weigendb, F., Calculations of current densities and aromatic pathways in cyclic porphyrin and isoporphyrin arrays. Physical Chemistry Chemical Physics 2017, 19 (20), 12794-12803.

17. Hamad, W., Cellulose nanocrystals in organic electronics. Abstracts of Papers of the American Chemical Society 2018, 256.

18. Zhang, C. F.; Chen, M.; Qian, D. J., Characterization and electrochemistry of interfacial selfassembled multi-manganese (III)-porphyrin arrays. Thin Solid Films 2009, 517 (13), 3760-3765. 
19. Goodenough, I.; Rawson, J.; Angiolillo, P.; Therien, M., Charge accommodation in n-doped ethynyl-bridged pi-conjugated porphyrin arrays. Abstracts of Papers of the American Chemical Society 2016, 252.

20. Calvo, J. J.; Angel, S. M.; So, M. C., Charge transport in metal-organic frameworks for electronics applications. Apl Materials 2020, 8 (5).

21. Paolesse, R.; Lvova, L.; Nardis, S.; Di Natale, C.; D'Amico, A.; Lo Castro, F., Chemical images by porphyrin arrays of sensors. Microchimica Acta 2008, 163 (1-2), 103-112.

22. Cho, W. J.; Cho, Y.; Min, S. K.; Kim, W. Y.; Kim, K. S., Chromium Porphyrin Arrays As Spintronic Devices. Journal of the American Chemical Society 2011, 133 (24), 9364-9369.

23. Lee, M.; Kim, H.; Kim, D.; Sim, E., Coherence length determination of meso-meso linked porphyrin arrays based on forward-backward pair trajectory analysis. Journal of Physical Chemistry A 2008, 112 (23), 5040-5045.

24. Lee, M.; Kim, H.; Kim, D.; Sim, E., Coherent excitation energy transfer of meso-meso linked porphyrin array. 2007 Pacific Rim Conference on Lasers and Electro-Optics, Vols 1-4 2007, 1388-1389.

25. Liu, Y.; Ke, C. F.; Zhang, H. Y.; Cui, J.; Ding, F., Complexation-induced transition of nanorod to network aggregates: Alternate porphyrin and cyclodextrin arrays. Journal of the American Chemical Society 2008, 130 (2), 600-605.

26. Magna, G.; Catini, A.; Kumar, R.; Palmacci, M.; Martinelli, E.; Paolesse, R.; di Natale, C., Conductive Photo-Activated Porphyrin-ZnO Nanostructured Gas Sensor Array. Sensors 2017, 17 (4).

27. Wang, M.; Baek, P.; Akbarinejad, A.; Barker, D.; Travas-Sejdic, J., Conjugated polymers and composites for stretchable organic electronics. Journal of Materials Chemistry C 2019, 7 (19), 55345552.

28. Tanaka, T.; Osuka, A., Conjugated porphyrin arrays: synthesis, properties and applications for functional materials. Chemical Society Reviews 2015, 44 (4), 943-969.

29. Crossley, M. J.; Sheehan, C. S.; Khoury, T.; Reimers, J. R.; Sintic, P. J., Construction of building blocks for extended porphyrin arrays by nitration of porphyrin-2,3-diones and quinoxalino[2,3b]porphyrins. New Journal of Chemistry 2008, 32 (2), 340-352.

30. Iritani, K.; Tahara, K.; Hirose, K.; De Feyter, S.; Tobe, Y., Construction of cyclic arrays of Znporphyrin units and their guest binding at the solid-liquid interface. Chemical Communications 2016, 52 (100), 14419-14422.

31. Hutchison, J. A.; Sintic, P. J.; Brotherhood, P. R.; Scholes, C.; Blake, I. M.; Ghiggino, K. P.; Crossley, M. J., Control of Photoinduced Charge Transfer Lifetimes in Porphyrin Arrays by Ligand Addition. Journal of Physical Chemistry C 2009, 113 (27), 11796-11804.

32. Ma, L. C.; Dai, S. X.; Zhan, X. W.; Liu, X. Y.; Li, Y., Convenient fabrication of conjugated polymer semiconductor nanotubes and their application in organic electronics. Royal Society Open Science 2018, 5 (8).

33. Trinh, T. M. N.; Nierengarten, I.; Ben Aziza, H.; Meichsner, E.; Holler, M.; Chesse, M.; Abidi, R.; Bijani, C.; Coppel, Y.; Maisonhaute, E.; Delavaux-Nicot, B.; Nierengarten, J. F., Coordination-Driven Folding in Multi-Zn-II-Porphyrin Arrays Constructed on a Pillar[5]arene Scaffold. Chemistry-a European Journal 2017, 23 (46), 11011-11021.

34. Capuano, R.; Pomarico, G.; Paolesse, R.; Di Natale, C., Corroles-Porphyrins: A Teamwork for Gas Sensor Arrays. Sensors 2015, 15 (4), 8121-8130.

35. Bernhard, S. S. R.; Locke, G. M.; Plunkett, S.; Meindl, A.; Flanagan, K. J.; Senge, M. O., Cubane Cross-Coupling and Cubane-Porphyrin Arrays. Chemistry-a European Journal 2018, 24 (5), 1026-1030.

36. Nakamura, Y.; Aratani, N.; Osuka, A., Cyclic porphyrin arrays as artificial photosynthetic antenna: Synthesis and excitation energy transfer. Chemical Society Reviews 2007, 36 (6), 831-845.

37. Muftakhov, M. V.; Khatymov, R. V.; Tuktarov, R. F., Decomposition of Aromatic Compounds Relevant to Organic Electronics under Exposure to Low-Energy Electrons. Technical Physics 2018, 63 (12), 1854-1860. 
38. Yang, J. S.; Yoo, H.; Aratani, N.; Osuka, A.; Kim, D., Determination of the Superradiance Coherence Length of Directly Linked Linear Porphyrin Arrays at the Single-Molecule Level. Angewandte Chemie-International Edition 2009, 48 (24), 4323-4327.

39. Ham, S.; Lee, J. E.; Song, S.; Peng, X. B.; Hori, T.; Aratani, N.; Osuka, A.; Sim, E.; Kim, D., Direct observation of structural properties and fluorescent trapping sites in macrocyclic porphyrin arrays at the single-molecule level. Physical Chemistry Chemical Physics 2016, 18 (5), 3871-3877.

40. $\quad$ Song, C. H.; Back, S. Y.; Yu, S. I.; Lee, H. J.; Kim, B. S.; Yang, N. Y.; Jeong, S. H.; Ahn, H., Direct-Patterning of Porphyrin Dot Arrays and Lines Using Electrohydrodynamic Jet Printing. Journal of Nanoscience and Nanotechnology 2012, 12 (1), 475-480.

41. Aratani, N.; Kim, D.; Osuka, A., Discrete Cyclic Porphyrin Arrays as Artificial Light-Harvesting Antenna. Accounts of Chemical Research 2009, 42 (12), 1922-1934.

42. Fendt, L. A.; Bouamaied, I.; Thoni, S.; Amiot, N.; Stulz, E., DNA as supramolecular scaffold for porphyrin arrays on the nanorneter scale. Journal of the American Chemical Society 2007, 129 (49), 15319-15329.

43. Payne, A. J.; Rice, N. A.; McAfee, S. M.; Lo, S.; Josse, P.; Cabanetos, C.; Risko, C.; Lessard, B. H.; Welch, G. C., Donor or Acceptor? How Selection of the Rylene Imide End Cap Impacts the Polarity of pi-Conjugated Molecules for Organic Electronics. Acs Applied Energy Materials 2018, 1 (9), 4906-4916.

44. Fujimoto, J.; Manseki, K.; Miyaji, H., Dye-sensitized Solar Cells Using Supramolecular Porphyrin Arrays Inspired by pi-Stacking Structures of Photosynthetic Light-harvesting Complexes. Chemistry Letters 2014, 43 (2), 207-209.

45. Luo, L.; Lin, C. J.; Tsai, C. Y.; Wu, H. P.; Li, L. L.; Lo, C. F.; Lin, C. Y.; Diau, E. W. G., Effects of aggregation and electron injection on photovoltaic performance of porphyrin-based solar cells with oligo(phenylethynyl) links inside $\mathrm{TiO} 2$ and $\mathrm{A} 12 \mathrm{O} 3$ nanotube arrays. Physical Chemistry Chemical Physics 2010, 12 (5), 1064-1071.

46. Bin, Z. Y.; Liu, Z. Y.; Qiu, Y.; Duan, L., Efficient n-Dopants and Their Roles in Organic Electronics. Advanced Optical Materials 2018, 6 (18).

47. Sugawa, K.; Yamaguchi, D.; Tsunenari, N.; Uchida, K.; Tahara, H.; Takeda, H.; Tokuda, K.; Jin, S.; Kusaka, Y.; Fukuda, N.; Ushijima, H.; Akiyama, T.; Watanuki, Y.; Nishimiya, N.; Otsuki, J.; Yamada, S., Efficient Photocurrent Enhancement from Porphyrin Molecules on Plasmonic Copper Arrays: Beneficial Utilization of Copper Nanoanntenae on Plasmonic Photoelectric Conversion Systems. Acs Applied Materials \& Interfaces 2017, 9 (1), 750-762.

48. Ouyang, Q.; Zhu, Y. Z.; Zhang, C. H.; Yan, K. Q.; Li, Y. C.; Zheng, J. Y., An Efficient PIFAMediated Synthesis of Fused Diporphyrin and Triply-Singly Interlacedly Linked Porphyrin Array. Organic Letters 2009, 11 (22), 5266-5269.

49. Souto, M.; Strutynski, K.; Melle-Franco, M.; Rocha, J., Electroactive Organic Building Blocks for the Chemical Design of Functional Porous Frameworks (MOFs and COFs) in Electronics. Chemistrya European Journal 2020.

50. Tabbi, G.; Di Mauro, G.; Purrello, R.; Bonomo, R. P., Electrochemical characterization of ordered arrays of metallo-porphyrins in aqueous solution. Dalton Transactions 2011, 40 (16), 4223-4229.

51. Kim, J.; Yamamoto, K.; Iimura, S.; Ueda, S.; Hosono, H., Electron Affinity Control of Amorphous Oxide Semiconductors and Its Applicability to Organic Electronics. Advanced Materials Interfaces 2018, 5 (23).

52. Cho, S.; Yoon, M. C.; Kim, K. S.; Kim, P.; Kim, D., Electron delocalization in various triply linked zinc(II) porphyrin arrays: role of antiaromatic junctions between aromatic porphyrins. Physical Chemistry Chemical Physics 2011, 13 (36), 16175-16181.

53. Rawson, J.; Angiolillo, P. J.; Frail, P. R.; Goodenough, I.; Therien, M. J., Electron Spin Relaxation of Hole and Electron Polarons in pi-Conjugated Porphyrin Arrays: Spintronic Implications. Journal of Physical Chemistry B 2015, 119 (24), 7681-7689. 
54. Lazarides, T.; Kuhri, S.; Charalambidis, G.; Panda, M. K.; Guldi, D. M.; Coutsolelos, A. G., Electron vs Energy Transfer in Arrays Featuring Two Bodipy Chromophores Axially Bound to a Sn(IV) Porphyrin via a Phenolate or Benzoate Bridge. Inorganic Chemistry 2012, 51 (7), 4193-4204.

55. High, J. S.; Virgil, K. K.; Jakubikova, E., Electronic Structure and Absorption Properties of Strongly Coupled Porphyrin-Perylene Arrays. Journal of Physical Chemistry A 2015, 119 (38), 9879 9888.

56. Jiang, H.; Hu, W. P., The Emergence of Organic Single-Crystal Electronics. Angewandte Chemie-International Edition 2020, 59 (4), 1408-1428.

57. Zvezdin, A.; Di Mauro, E.; Rho, D.; Santato, C.; Khalil, M., En route toward sustainable organic electronics. Mrs Energy \& Sustainability 2020, 7.

58. Zhu, P. H.; Wang, P. P.; Kan, T. L.; Sun, G. Q.; Zhang, Y.; Yu, J. H., An enhanced photoelectrochemical immunosensing platform: Supramolecular donor-acceptor arrays by assembly of porphyrin and C-60. Biosensors \& Bioelectronics 2015, 68, 604-610.

59. Novikov, A. V.; Kuznetsova, L. I.; Dremova, N. N.; Parfenov, A. A.; Troshin, P. A., Environment-friendly aqueous processing of [60]fullerene semiconducting films for truly green organic electronics. Journal of Materials Chemistry C 2020, 8 (2), 495-499.

60. Li, J. L.; Cao, J. J.; Duan, L. L.; Zhang, H. L., Evolution of Isoindigo-Based Electron-Deficient Units for Organic Electronics: From Natural Dyes to Organic Semiconductors. Asian Journal of Organic Chemistry 2018, 7 (11), 2147-2160.

61. Rawson, J.; Angiolillo, P. J.; Therien, M. J., Exceptional delocalization of electrons in conjugated porphyrin arrays. Abstracts of Papers of the American Chemical Society 2012, 244.

62. Yang, J.; Park, M.; Yoon, Z. S.; Hori, T.; Peng, X. B.; Aratani, N.; Dedecker, P.; Hotta, J. I.; Uji-I, H.; Sliwa, M.; Hofkens, J.; Osuka, A.; Kim, D., Excitation energy migration processes in cyclic porphyrin Arrays probed by single molecule spectroscopy. Journal of the American Chemical Society 2008, 130 (6), 1879-1884.

63. Kim, P.; Ikeda, T.; Lim, J. M.; Park, J.; Lim, M.; Aratani, N.; Osuka, A.; Kim, D., Excitedstate energy relaxation dynamics of triply linked $\mathrm{Zn}(\mathrm{II})$ porphyrin arrays. Chemical Communications 2011, 47 (15), 4433-4435.

64. Kim, T.; Oh, J.; Jiang, H. W.; Tanaka, T.; Osuka, A.; Kim, D., Exciton coupling dynamics in syn- and anti-type beta-beta linked Zn(II) porphyrin linear arrays. Physical Chemistry Chemical Physics 2016, 18 (33), 23105-23110.

65. Hori, T.; Nakamura, Y.; Aratani, N.; Osuka, A., Exploration of electronically interactive cyclic porphyrin arrays. Journal of Organometallic Chemistry 2007, 692 (1-3), 148-155.

66. Aratani, N.; Osuka, A., Exploration of Giant Functional Porphyrin Arrays. Bulletin of the Chemical Society of Japan 2015, 88 (1), 1-27.

67. Titi, H. M.; Nandi, G.; Tripuramallu, B. K.; Goldberg, I., Exploring Supramolecular SelfAssembly of Tetraarylporphyrins by Halogen Interactions. 3. Tin(L)(2)(A(2)B(2)-Porphyrin) Arrays Supported by Concerted Halogen and Hydrogen Bonding. Crystal Growth \& Design 2015, 15 (6), 3063 3075.

68. Luzanov, A. V., Extended quasi-correlated orbitals with long-range effects: Application to organic single-molecule electronics. Functional Materials 2020, 27 (1), 147-158.

69. Sugawa, K.; Uchida, K.; Takeshima, N.; Jin, S.; Tsunenari, N.; Takeda, H.; Kida, Y.; Akiyama, T.; Otsuki, J.; Takase, K.; Yamada, S., Extraordinary enhancement of porphyrin photocurrent utilizing plasmonic silver arrays. Nanoscale 2016, 8 (34), 15467-15472.

70. Sanchez-Vergara, M. E.; Guevara-Martinez, E.; Arreola-Castillo, A.; Mendoza-Sevilla, A., Fabrication of Hybrid Membranes Containing Nylon-11 and Organic Semiconductor Particles with Potential Applications in Molecular Electronics. Polymers 2020, 12 (1).

71. La, D. D.; Thi, H. P. N.; Kim, Y. S.; Rananaware, A.; Bhosale, S. V., Facile fabrication of $\mathrm{Cu}(\mathrm{II})$-porphyrin MOF thin films from tetrakis(4-carboxyphenyl) porphyrin and $\mathrm{Cu}(\mathrm{OH})(2)$ nanoneedle array. Applied Surface Science 2017, 424, 145-150. 
72. Slodek, A.; Zych, D.; Maron, A.; Golba, S.; Schab-Balcerzak, E.; Janeczek, H.; Siwy, M.; Mackowski, S., Fluorene vs carbazole substituent at quinoline core toward organic electronics. Dyes and Pigments 2019, 166, 98-106.

73. Kose, K.; Motoyanagi, J.; Kusukawa, T.; Osuka, A.; Tsuda, A., Formation of Discrete Ladders and a Macroporous Xerogel Film by the Zipperlike Dimerization of Meso-Meso-Linked Zinc(II) Porphyrin Arrays with Di(pyrid-3-yl)acetylene. Angewandte Chemie-International Edition 2015, 54 (30), 8673-8678.

74. Yoshimoto, S.; Sato, K.; Sugawara, S.; Chen, Y.; Ito, O.; Sawaguchi, T.; Niwa, O.; Itaya, K., Formation of supramolecular nanobelt arrays consisting of cobalt(II) "Picket-Fence" porphyrin on Au surfaces. Langmuir 2007, 23 (2), 809-816.

75. Zenkevich, E. I.; von Borczyskowski, C. W., Formation Principles and Excited States Relaxation in Self-Assembled Complexes: Multiporphyrin Arrays and "Semiconductor CdSe/ZnS Quantum DotPorphyrin" Nanocomposites. Handbook of Porphyrin Science with Applications to Chemistry, Physics, Materials Science, Engineering, Biology and Medicine, Vol 22: Biophysical and Physicochemical Studies of Tetrapyrroles 2012, 22, 67-168.

76. Urbani, M.; Iehl, J.; Osinska, I.; Louis, R.; Holler, M.; Nierengarten, J. F., Formyl-Porphyrin and Formyl-Fullerenoporphyrin Building Blocks for the Construction of Multiporphyrin Arrays. European Journal of Organic Chemistry 2009, (22), 3715-3725.

77. Sariciftci, N. S., From Organic Electronics to Bio-organic Electronics. Nonlinear Optics Quantum Optics-Concepts in Modern Optics 2019, 50 (1-3), 137-144.

78. D'Urso, A.; Fragala, M. E.; Purrello, R., From self-assembly to noncovalent synthesis of programmable porphyrins' arrays in aqueous solution. Chemical Communications 2012, 48 (66), 81658176.

79. Xu, M.; Pradhan, S.; Pal, R. K.; Yadavalli, V. K., Fully organic, flexible, and biodegradable components for bioinspired electronics. Micro- and Nanotechnology Sensors, Systems, and Applications Xi 2019, 10982.

80. AbdulAlmohsin, S.; Cui, J. B., Graphene-Enriched P3HT and Porphyrin-Modified ZnO Nanowire Arrays for Hybrid Solar Cell Applications. Journal of Physical Chemistry C 2012, 116 (17), 9433-9438.

81. Balogun, S. W.; James, O. O.; Sanusi, Y. K.; Olayinka, O. H., Green synthesis and characterization of zinc oxide nanoparticles using bashful (Mimosa pudica), leaf extract: a precursor for organic electronics applications. Sn Applied Sciences 2020, 2 (3).

82. Baciu, B. C.; de Ara, T.; Sabater, C.; Untiedt, C.; Guijarro, A., Helical nanostructures for organic electronics: the role of topological sulfur in ad hoc synthesized dithia[7]helicenes studied in the solid state and on a gold surface. Nanoscale Advances 2020, 2 (5), 1921-1926.

83. Chiba, Y.; Liu, M.; Tachibana, Y.; Fujihara, T.; Tsuji, Y.; Terao, J., Hetero Face-to-Face Porphyrin Array with Cooperative Effects of Coordination and Host-Guest Complexation. Chemistry-an Asian Journal 2017, 12 (15), 1900-1904.

84. Lo, P. C.; Leng, X. B.; Ng, D. K. P., Hetero-arrays of porphyrins and phthalocyanines. Coordination Chemistry Reviews 2007, 251 (17-20), 2334-2353.

85. Yoon, M. C.; Yoon, Z. S.; Cho, S.; Kim, D.; Takagi, A.; Matsumoto, T.; Kawai, T.; Hori, T.; Peng, X. B.; Aratani, N.; Osuka, A., A hexagonal prismatic porphyrin array: Synthesis, STM detection, and efficient energy hopping in near-infrared region. Journal of Physical Chemistry A 2007, 111 (38), 9233-9239.

86. Gumyusenge, A.; Mei, J. G., High Temperature Organic Electronics. Mrs Advances 2020, 5 (10), 505-513.

87. Saeki, A.; Kranthiraja, K., A high throughput molecular screening for organic electronics via machine learning: present status and perspective. Japanese Journal of Applied Physics 2020, 59.

88. Liu, Y. F.; Ding, T.; Chen, X. T.; Bai, F. Q.; Genco, A.; Wang, H. R.; Chen, C.; Chen, P.; Mazzeo, M.; Zhang, Y. T.; Duan, Y., Highly Conductive Alkaline-Earth Metal Electrodes: The Possibility of Maintaining Both Low Work Function and Surface Stability for Organic Electronics. Advanced Optical Materials 2020. 
89. Yang, C.; Liu, Q. F.; Zang, L. M.; Qiu, J. H.; Wang, X.; Wei, C.; Qiao, X.; Hu, L.; Yang, J.; Song, G.; Liu, C. J., High-Performance Yarn Supercapacitor Based on Metal-Inorganic-Organic Hybrid Electrode for Wearable Electronics. Advanced Electronic Materials 2019, 5 (1).

90. Piotrowska, K.; Verdingovas, V.; Ambat, R., Humidity-related failures in electronics: effect of binary mixtures of weak organic acid activators. Journal of Materials Science-Materials in Electronics 2018, 29 (20), 17834-17852.

91. Zetola, N. M.; Modongo, C.; Matlhagela, K.; Sepako, E.; Matsiri, O.; Tamuhla, T.; Mbongwe, B.; Martinelli, E.; Sirugo, G.; Paolesse, R.; Di Natale, C., Identification of a Large Pool of Microorganisms with an Array of Porphyrin Based Gas Sensors. Sensors 2016, 16 (4).

92. Singh, A. K.; Chou, W. F.; Jia, X. J.; Wang, C. Y.; Fuentes-Hernandez, C.; Kippelen, B.; Graham, S., Impact of interface materials on side permeation in indirect encapsulation of organic electronics. Journal of Vacuum Science \& Technology A 2020, 38 (3).

93. Bronshtein, I.; Leitus, G.; Rybtchinski, B., In Situ Growth of High Quality Crystals for Organic Electronics. Acs Applied Electronic Materials 2020, 2 (3), 790-795.

94. Singleton, D. G.; Hussain, R.; Siligardi, G.; Kumar, P.; Hrdlicka, P. J.; Berova, N.; Stulz, E., Increased duplex stabilization in porphyrin-LNA zipper arrays with structure dependent exciton coupling. Organic \& Biomolecular Chemistry 2016, 14 (1), 149-157.

95. Zhang, L. J.; Jiang, X. X.; Jiang, W.; Li, S.; Chi, Y. X.; Liu, H.; Zhang, M. Y.; Li, J. Y.; Fang, M.; Pan, B.; Chen, Y. L.; Shen, C. N.; Guo, X.; Li, R.; Guo, L.; Su, Y. W., Infrared Skin-Like Active Stretchable Electronics Based on Organic-Inorganic Composite Structures for Promotion of Cutaneous Wound Healing. Advanced Materials Technologies 2019, 4 (8).

96. Brewer, A.; Siligardi, G.; Neylon, C.; Stulz, E., Introducing structural flexibility into porphyrinDNA zipper arrays. Organic \& Biomolecular Chemistry 2011, 9 (3), 777-782.

97. Brewer, A.; Siligardi, G.; Neylon, C.; Stulz, E., Introducing structural flexibility into porphyrinDNA zipper arrays (vol 9, pg 777, 2011). Organic \& Biomolecular Chemistry 2011, 9 (24), 8505-8506.

98. Jiang, Y.; Qin, D. D.; Fan, Y. R.; Guo, H. X.; Wang, S. X.; Ning, X. M.; Lu, X. Q., Investigation of photoinduced electron transfer on $\mathrm{TiO} 2$ nanowire arrays/porphyrin composite via scanning electrochemical microscopy. Rsc Advances 2015, 5 (70), 56697-56703.

99. Romele, P.; Ghittorelli, M.; Kovacs-Vajna, Z. M.; Torricelli, F., Ion buffering and interface charge enable high performance electronics with organic electrochemical transistors. Nature Communications 2019, 10.

100. Muresan, A. Z.; Holten, D.; Bocian, D. F.; Lindsey, J. S., Isotopically labeled porphyrins for studies of ground-state hole transfer in multiporphyrin arrays. Abstracts of Papers of the American Chemical Society 2007, 234.

101. Kozaki, M.; Uetomo, A.; Suzuki, S.; Okada, K., A Light-Harvesting Array Composed of Porphyrins and Rigid Backbones. Organic Letters 2008, 10 (20), 4477-4480.

102. Kim, J. W.; Jang, Y. H.; Ku, G. M.; Kim, S.; Lee, E.; Cho, K.; Lim, K. I.; Lee, W. H., Liquid coplanar-gate organic/graphene hybrid electronics for label-free detection of single and double-stranded DNA molecules. Organic Electronics 2018, 62, 163-167.

103. Vollbrecht, J.; Oechsle, P.; Stepen, A.; Hoffmann, F.; Paradies, J.; Meyers, T.; Hilleringmann, U.; Schmidtke, J.; Kitzerow, H., Liquid crystalline dithienothiophene derivatives for organic electronics. Organic Electronics 2018, 61, 266-275.

104. Tajima, K., Look beyond the surface: recent progress in applications of surface-segregated monolayers for organic electronics. Polymer Journal 2019, 51 (11), 1117-1126.

105. Klain, C.; Linde, S.; Shikler, R.; Sarusi, G., Low work function Ca doped graphene as a transparent cathode for organic opto-electronics and OLEDs. Carbon 2020, 157, 255-261.

106. Bullard, G.; Tassinari, F.; Ko, C. H.; Mondal, A. K.; Wang, R.; Mishra, S.; Naaman, R.; Therien, M. J., Low-Resistance Molecular Wires Propagate Spin-Polarized Currents. Journal of the American Chemical Society 2019, 141 (37), 14707-14711. 
107. Peng, X. B.; Huang, Y. Y.; Gao, C.; Peng, J. B.; Komatsu, N.; Osuka, A.; Cao, Y., Macroscopic Films of Porphyrin Nanowell-Arrays via Solvent Diffusion-Induced Self-Assembly. Journal of Physical Chemistry C 2010, 114 (43), 18449-18454.

108. Lee, J. H.; Jintoku, H.; Okazaki, Y.; Sagawa, T.; Takafuji, M.; Ihara, H., Manipulation of discrete porphyrin-fullerene nanopillar arrays regulated by the phase separated infiltration of polymer in ternary blended organic thin-films. Solar Energy Materials and Solar Cells 2015, 140, 428-438.

109. Mitra, K. Y.; Alalawe, A.; Voigt, S.; Boeffel, C.; Baumann, R. R., Manufacturing of All InkjetPrinted Organic Photovoltaic Cell Arrays and Evaluating Their Suitability for Flexible Electronics. Micromachines 2018, 9 (12).

110. Teo, R. D.; Wang, R. B.; Smithwick, E. R.; Migliore, A.; Therien, M. J.; Beratan, D. N., Mapping hole hopping escape routes in proteins. Proceedings of the National Academy of Sciences of the United States of America 2019, 116 (32), 15811-15816.

111. Emandi, G.; Shaker, Y. M.; Flanagan, K. J.; O'Brien, J. M.; Senge, M. O., Merging Triptycene, BODIPY and Porphyrin Chemistry: Synthesis and Properties of Mono- and Trisubstituted Triptycene Dye Arrays. European Journal of Organic Chemistry 2017, (45), 6680-6692.

112. Thamyongkit, P.; Muresan, A. Z.; Diers, J. R.; Holten, D.; Bocian, D. F.; Lindsey, J. S., MesoC-13-labeled porphyrins for studies of ground-state hole transfer in multiporphyrin arrays. Journal of Organic Chemistry 2007, 72 (14), 5207-5217.

113. Mori, H.; Osuka, A., meso-meso Directly-linked trimeric and pentameric electron-deficient porphyrin-hexaphyrin hybrid arrays. Journal of Porphyrins and Phthalocyanines 2016, 20 (1-4), 245-253. 114. Mori, H.; Tanaka, T.; Lee, S.; Lim, J. M.; Kim, D.; Osuka, A., meso-meso Linked Porphyrin[26]Hexaphyrin-Porphyrin Hybrid Arrays and Their Triply Linked Tapes Exhibiting Strong Absorption Bands in the NIR Region. Journal of the American Chemical Society 2015, 137 (5), 2097-2106.

115. Zhang, S. M.; Kim, J. O.; Li, Y. J.; Wen, B.; Zhou, M. B.; Liu, S. B.; Aratani, N.; Xu, L.; Kim, D.; Song, J. X., meso-to-meso 2,5-Pyrrolylene bridged zig-zag porphyrin arrays. Chemical Communications 2017, 53 (83), 11488-11491.

116. Wu, J.; Chen, J. H.; Wang, C.; Zhou, Y.; Ba, K.; Xu, H.; Bao, W. Z.; Xu, X. H.; Carlsson, A.; Lazar, S.; Meingast, A.; Sun, Z. Z.; Deng, H. X., Metal-Organic Framework for Transparent Electronics. Advanced Science 2020, 7 (8).

117. Yu, J. X.; Mathew, S.; Flavel, B. S.; Quinton, J. S.; Johnston, M. R.; Shapter, J. G., Mixed assembly of ferrocene/porphyrin onto carbon nanotube arrays towards multibit information storage. 2008 International Conference on Nanoscience and Nanotechnology 2008, 176-179.

118. Santi, S.; Rossi, S., Molecular design of star-shaped benzotrithiophene materials for organic electronics. Tetrahedron Letters 2019, 60 (36).

119. Heo, J. H.; Ikeda, T.; Lim, J. M.; Aratani, N.; Osuka, A.; Kim, D., Molecular-Shape-Dependent Photophysical Properties of meso-beta Doubly Linked Zn(II) Porphyrin Arrays and Their Indene-Fused Analogues. Journal of Physical Chemistry B 2010, 114 (45), 14528-14536.

120. Abe, S.; Kobayashi, H.; Kiba, T.; Watari, F.; Sato, S. I., Morphology and Photophysical Properties of One-Dimensional Arrayed Porphyrin Aggregates Assisted by Cyclodextrin Inclusion Complexation. Molecular Crystals and Liquid Crystals 2012, 566, 151-157.

121. Smith, A. R. G.; Ruggles, J. L.; Yu, A. M.; Gentle, I. R., Multilayer Nanostructured Porphyrin Arrays Constructed by Layer-by-Layer Self-Assembly. Langmuir 2009, 25 (17), 9873-9878.

122. Atefi, F.; McMurtrie, J. C.; Arnold, D. P., Multiporphyrin coordination arrays based on complexation of magnesium(II) porphyrins with porphyrinylphosphine oxides. Dalton Transactions 2007, (21), 2163-2170.

123. He, Z. R.; Zhang, Z. Y.; Bi, S., Nanoparticles for organic electronics applications. Materials Research Express 2020, 7 (1).

124. Cao, J.; Hu, D. C.; Liu, J. C.; Li, R. Z.; Jin, N. Z., Nanostructured TiO2 modified with acetohydrazide zinc porphyrin well-arrays for supramolecular solar cells. Organic Electronics 2014, 15 (2), 509-516. 
125. Nowak-Krol, A.; Shoyama, K.; Stolte, M.; Wurthner, F., Naphthalene and perylene diimides better alternatives to fullerenes for organic electronics? Chemical Communications 2018, 54 (98), 13763 13772.

126. Ariga, K.; Hill, J. P.; Wakayama, Y.; Akada, M.; Barrena, E.; de Oteyza, D. G., New aspects of porphyrins and related compounds: self-assembled structures in two-dimensional molecular arrays.

Journal of Porphyrins and Phthalocyanines 2009, 13 (1), 22-34.

127. Caironi, M.; Muller, C.; von Hauff, E.; Sommer, M., New Materials for Organic Electronics: Improved Properties to Tackle Application Challenges. Advanced Electronic Materials 2018, 4 (10).

128. Buchner, F.; Seufert, K.; Auwarter, W.; Heim, D.; Barth, J. V.; Flechtner, K.; Gottfried, J. M.; Steinruck, H. P.; Marbach, H., NO-Induced Reorganization of Porphyrin Arrays. Acs Nano 2009, 3 (7), 1789-1794.

129. Korzec, M.; Kotowicz, S.; Rzycka-Korzec, R.; Schab-Balcerzak, E.; Malecki, J. G.; Czichy, M.; Lapkowski, M., Novel beta-ketoenamines versus azomethines for organic electronics:

characterization of optical and electrochemical properties supported by theoretical studies. Journal of Materials Science 2020, 55 (9), 3812-3832.

130. Yutronkie, N. J.; Grant, T. M.; Melville, O. A.; Lessard, B. H.; Brusso, J. L., Old Molecule, New Chemistry: Exploring Silicon Phthalocyanines as Emerging N-Type Materials in Organic Electronics. Materials 2019, 12 (8).

131. Pirotte, G.; Verstappen, P.; Vanderzande, D.; Maes, W., On the "True" Structure of Push-PullType Low-Bandgap Polymers for Organic Electronics. Advanced Electronic Materials 2018, 4 (10).

132. Ragni, R.; Punzi, A.; Babudri, F.; Farinola, G. M., Organic and Organometallic Fluorinated Materials for Electronics and Optoelectronics: A Survey on Recent Research. European Journal of Organic Chemistry 2018, 2018 (27-28), 3500-3519.

133. Goswami, S.; Goswami, S.; Venkatesan, T., An organic approach to low energy memory and brain inspired electronics. Applied Physics Reviews 2020, 7 (2).

134. Sinha, S.; Li, Z.; Noh, Y.; Chon, K.; Cao, Y.; Sotzing, G., Organic conductive polymers as printed electronics on fabrics for wearable electronics. Abstracts of Papers of the American Chemical Society 2019, 257.

135. Wang, Y.; Sun, L. J.; Wang, C.; Yang, F. X.; Ren, X. C.; Zhang, X. T.; Dong, H. L.; Hu, W. P., Organic crystalline materials in flexible electronics. Chemical Society Reviews 2019, 48 (6), 14921530 .

136. Black, C.; Darie, R.; Borton, D., Organic Electronics for Artificial Touch. Trends in Neurosciences 2018, 41 (9), 568-570.

137. Seck, M.; Mohammadian, N.; Diallo, A. K.; Faraji, S.; Erouel, M.; Bouguila, N.; Ndiaye, D.; Khirouni, K.; Majewski, L. A., Organic FETs using biodegradable almond gum as gate dielectric: A promising way towards green electronics. Organic Electronics 2020, 83.

138. Ling, H. F.; Liu, S. H.; Zheng, Z. J.; Yan, F., Organic Flexible Electronics. Small Methods 2018, $2(10)$.

139. Yu, K.; Rich, S.; Lee, S.; Fukuda, K.; Yokota, T.; Someya, T., Organic Photovoltaics: Toward Self-Powered Wearable Electronics. Proceedings of the Ieee 2019, 107 (10), 2137-2154.

140. Zhang, X. T.; Dong, H. L.; Hu, W. P., Organic Semiconductor Single Crystals for Electronics and Photonics. Advanced Materials 2018, 30 (44).

141. Lau, W. Y.; Hopkins, M., Organized arrays of functional molecules supported by galliumporphyrin monolayers on HOPG. Abstracts of Papers of the American Chemical Society 2015, 249.

142. He, W. L.; Fang, F.; Ma, D. M.; Chen, M.; Qian, D. J.; Liu, M. H., Palladium-directed selfassembly of multi-titanium(IV)-porphyrin arrays on the substrate surface as sensitive ultrathin films for hydrogen peroxide sensing, photocurrent generation, and photochromism of viologen. Applied Surface Science 2018, 427, 1003-1010.

143. Hu, G. F.; Liu, R.; Alexy, E. J.; Mandal, A. K.; Bocian, D. F.; Holten, D.; Lindsey, J. S., Panchromatic chromophore-tetrapyrrole light-harvesting arrays constructed from Bodipy, perylene, 
terrylene, porphyrin, chlorin, and bacteriochlorin building blocks. New Journal of Chemistry 2016, 40 (9), 8032-8052.

144. Ji, D. Y.; Li, T.; Fuchs, H., Patterning and applications of nanoporous structures in organic electronics. Nano Today 2020, 31.

145. Sakaguchi, K.; Kamimura, T.; Uno, H.; Mori, S.; Ozako, S.; Nobukuni, H.; Ishida, M.; Tani, F., Phenothiazine-Bridged Cyclic Porphyrin Dimers as High-Affinity Hosts for Fullerenes and Linear Array of C-60 in Self-Assembled Porphyrin Nanotube. Journal of Organic Chemistry 2014, 79 (7), 29802992.

146. Popere, B. C.; Sanoja, G. E.; Thomas, E. M.; Schauser, N. S.; Jones, S. D.; Bartels, J. M.; Helgeson, M. E.; Chabinyc, M. L.; Segalman, R. A., Photocrosslinking polymeric ionic liquids via anthracene cycloaddition for organic electronics. Journal of Materials Chemistry C 2018, 6 (32), 87628769.

147. de Tacconi, N. R.; Chanmanee, W.; Rajeshwar, K.; Rochford, J.; Galoppini, E., Photoelectrochemical Behavior of Polychelate Porphyrin Chromophores and Titanium Dioxide Nanotube Arrays for Dye-Sensitized Solar Cells. Journal of Physical Chemistry C 2009, 113 (7), 2996-3006.

148. Yoon, M. C.; Noh, S. B.; Tsuda, A.; Nakamura, Y.; Osuka, A.; Kim, D., Photophysics of meso-beta doubly linked $\mathrm{Ni}$ (II) porphyrin arrays: Large two-photon absorption cross-section and fast energy relaxation dynamics. Journal of the American Chemical Society 2007, 129 (33), 10080-+.

149. Zhao, Q. D.; Yu, M.; Xie, T. F.; Peng, L. L.; Wang, P.; Wang, D. J., Photovoltaic properties of a $\mathrm{ZnO}$ nanorod array affected by ethanol and liquid-crystalline porphyrin. Nanotechnology 2008, 19 (24). 150. Alam, M. M.; Bolze, F.; Daniel, C.; Flamigni, L.; Gourlaouen, C.; Heitz, V.; Jenni, S.; Schmitt, J.; Sour, A.; Ventura, B., pi-Extended diketopyrrolopyrrole-porphyrin arrays: one- and twophoton photophysical investigations and theoretical studies. Physical Chemistry Chemical Physics 2016, 18 (31), 21954-21965.

151. Johnson, J. A.; Lin, Q. P.; Wu, L. C.; Obaidi, N.; Olson, Z. L.; Reeson, T. C.; Chen, Y. S.; Zhang, J., A "pillar-free", highly porous metalloporphyrinic framework exhibiting eclipsed porphyrin arrays. Chemical Communications 2013, 49 (27), 2828-2830.

152. Mao, Y. Y.; Zhao, Q.; Pan, T. T.; Shi, J. Y.; Jiang, S. M.; Chen, M. W.; Zhou, B. P.; Tian, Y. Q., Platinum porphyrin/3-(trimethoxysily)propylmethacrylate functionalized flexible PDMS micropillar arrays as optical oxygen sensors. New Journal of Chemistry 2017, 41 (13), 5429-5435.

153. Wu, Y.; Liu, Y.; Emrick, T.; Russell, T. P., Polymer design to promote low work function surfaces in organic electronics. Progress in Polymer Science 2020, 103.

154. Yamamura, T.; Suzuki, S.; Taguchi, T.; Onoda, A.; Kamachi, T.; Okura, I., Porphyrin Arrays Responsive to Additives. Fluorescence Tuning. Journal of the American Chemical Society 2009, 131 (33), 11719-11726.

155. Ryan, A.; Gehrold, A.; Perusitti, R.; Pintea, M.; Fazekas, M.; Locos, O. B.; Blaikie, F.; Senge, M. O., Porphyrin Dimers and Arrays. European Journal of Organic Chemistry 2011, (29), 5817-5844.

156. Endo, M.; Fujitsuka, M.; Majima, T., Porphyrin light-harvesting arrays constructed in the recombinant tobacco mosaic virus scaffold. Chemistry-a European Journal 2007, 13 (31), 8660-8666.

157. Liu, Q. Y.; Zhu, J. Q.; Sun, T.; Zhou, H. Y.; Shao, Q.; Li, G. J.; Liu, X. D.; Yin, Y. S., Porphyrin nanotubes composed of highly ordered molecular arrays prepared by anodic aluminum template method. Rsc Advances 2013, 3 (8), 2765-2769.

158. Lvova, L.; Di Natale, C.; Paolesse, R., Porphyrin-based chemical sensors and multisensor arrays operating in the liquid phase. Sensors and Actuators B-Chemical 2013, 179, 21-31.

159. Bearinger, J. P.; Stone, G.; Dugan, L. C.; El Dasher, B.; Stockton, C.; Conway, J. W.; Kuenzler, T.; Hubbell, J. A., Porphyrin-based Photocatalytic Nanolithography A NEW FABRICATION TOOL FOR PROTEIN ARRAYS. Molecular \& Cellular Proteomics 2009, 8 (8), 1823-1831.

160. Maretina, I. A., Porphyrin-Ethynyl Arrays: Synthesis, Design, and Application. Russian Journal of General Chemistry 2009, 79 (7), 1544-1581. 
161. Shirsat, M. D.; Sarkar, T.; Kakoullis, J.; Myung, N. V.; Konnanath, B.; Spanias, A.; Mulchandani, A., Porphyrin-Functionalized Single-Walled Carbon Nanotube Chemiresistive Sensor Arrays for VOCs. Journal of Physical Chemistry C 2012, 116 (5), 3845-3850.

162. Chen, J. P.; Aratani, N.; Shinokubo, H.; Osuka, A., Post-Modification of meso-meso-Linked Porphyrin Arrays by Iridium and Rhodium Catalyses for Tuning of Energy Gap. Chemistry-an Asian Journal 2009, 4 (7), 1126-1133.

163. Zenkevich, E.; von Borczyskowski, C., Primary Photoevents in Self-Assembled Complexes: Multiporphyrin Arrays and "Semiconductor CdSe/ZnS Nanocrystal-Porphyrin" Composites.

Multiporphyrin Arrays: Fundamentals and Applications 2012, 217-288.

164. Mihara, N.; Yamada, Y.; Tanaka, K., Programmable Arrangement of Heterometal Ions in a Supramolecular Array of Porphyrin and Phthalocyanine. Bulletin of the Chemical Society of Japan 2017, 90 (4), 427-435.

165. Yang, X. U.; Zhang, D.; Tang, R. R.; Chen, X. H., Progress in the Synthesis and Application of Porphyrin-Perylene Arrays. Chinese Journal of Organic Chemistry 2009, 29 (12), 1906-1923.

166. Minamiki, T.; Kubota, R.; Sasaki, Y.; Asano, K.; Minami, T., Protein Assays on Organic Electronics: Rational Device and Material Designs for Organic Transistor-Based Sensors. Chemistryopen 2020, 9 (5), 573-581.

167. Haft, M.; Knohl, S., PTS is a new Member of the OE-A (Organic and Printed Electronics Association) Network: New Opportunities \& Possibilities. Wochenblatt Fur Papierfabrikation 2020, 148 (1).

168. Chen, M. L.; Yin, B. S.; Song, J. X., Recent Development of Constructing Porphyrin Arrays via Suzuki-Miyaura Cross-Coupling Reaction. Progress in Chemistry 2015, 27 (6), 641-654.

169. Li, W. T.; Zhang, H.; Shi, S. W.; Xu, J. X.; Qin, X.; He, Q. Q.; Yang, K. C.; Dai, W. B.; Liu, G.; Zhou, Q. G.; Yu, H. Z.; Silva, S. R. P.; Fahlman, M., Recent progress in silver nanowire networks for flexible organic electronics. Journal of Materials Chemistry C 2020, 8 (14), 4636-4674.

170. $\quad$ Fang, Y. Y.; Jiang, X. Q.; Ou, Z. P.; Michelin, C.; Desbois, N.; Gros, C. P.; Kadish, K. M., Redox properties of nitrophenylporphyrins and electrosynthesis of nitrophenyl-linked Zn porphyrin dimers or arrays. Journal of Porphyrins and Phthalocyanines 2014, 18 (8-9), 832-841.

171. Han, L.; Huang, Y. K.; Tang, W.; Chen, S. J.; Zhao, J. Q.; Guo, X. J., Reducing contact resistance in bottom contact organic field effect transistors for integrated electronics. Journal of Physics D-Applied Physics 2020, 53 (1).

172. Muresan, A. Z.; Thamyongkit, P.; Diers, J. R.; Holten, D.; Lindsey, J. S.; Bocian, D. F., Regiospecifically alpha-C-13-labeled porphyrins for studies of ground-state hole transfer in multiporphyrin arrays. Journal of Organic Chemistry 2008, 73 (18), 6947-6959.

173. Vijayaraghavan, S.; Auwarter, W.; Ecija, D.; Seufert, K.; Rusponi, S.; Houwaart, T.; Sautet, P.; Bocquet, M. L.; Thakur, P.; Stepanow, S.; Schlickum, U.; Etzkorn, M.; Brune, H.; Barth, J. V., Restoring the Co Magnetic Moments at Interfacial Co-Porphyrin Arrays by Site-Selective Uptake of Iron. Acs Nano 2015, 9 (4), 3605-3616.

174. Kwon, J. H.; Jeon, Y.; Choi, K. C., Robust Transparent and Conductive Gas Diffusion Multibarrier Based on Mg- and Al-Doped $\mathrm{ZnO}$ as Indium Tin Oxide-Free Electrodes for Organic Electronics. Acs Applied Materials \& Interfaces 2018, 10 (38), 32387-32396.

175. Spiess, H., Role of conformation of side groups in supramolecular organization of materials for organic electronics. Abstracts of Papers of the American Chemical Society 2019, 258.

176. Yang, J.; Lee, J. E.; Lee, C. Y.; Aratani, N.; Osuka, A.; Hupp, J. T.; Kim, D., The Role of Electronic Coupling in Linear Porphyrin Arrays Probed by Single-Molecule Fluorescence Spectroscopy. Chemistry-a European Journal 2011, 17 (33), 9219-9225.

177. Kim, D., The Role of Electronic Coupling in Various Porphyrin Arrays Probed by Raman and Single Molecule Fluorescence Spectroscopy. Xxii International Conference on Raman Spectroscopy 2010, 1267, 687-688. 
178. Yu, J. X.; Mathew, S.; Flavel, B. S.; Johnston, M. R.; Shapter, J. G., Ruthenium porphyrin functionalized single-walled carbon nanotube arrays - A step toward light harvesting antenna and multibit information storage. Journal of the American Chemical Society 2008, 130 (27), 8788-8796.

179. Sizov, A. S.; Agina, E. V.; Ponomarenko, S. A., Self-assembled interface monolayers for organic and hybrid electronics. Russian Chemical Reviews 2019, 88 (12), 1220-1247.

180. Shen, Y. T.; Deng, K.; Li, M.; Zhang, X. M.; Zhou, G.; Muellen, K.; Zeng, Q. D.; Wang, C., Self-assembling in fabrication of ordered porphyrins and phthalocyanines hybrid nano-arrays on HOPG. Crystengcomm 2013, 15 (27), 5526-5531.

181. Morisue, M.; Hoshino, Y.; Shimizu, K.; Shimizu, M.; Kuroda, Y., Self-complementary doublestranded porphyrin arrays assembled from an alternating pyridyl-porphyrin sequence. Chemical Science 2015, 6 (11), 6199-6206.

182. Rauch, V.; Conradt, J.; Takahashi, M.; Kanesato, M.; Wytko, J. A.; Kikkawa, Y.; Kalt, H.; Weiss, J., Self-organized porphyrin arrays on surfaces: the case of hydrophilic side chains and polar surfaces. Journal of Porphyrins and Phthalocyanines 2014, 18 (1-2), 67-75.

183. Park, S.; Heo, S. W.; Lee, W.; Inoue, D.; Jiang, Z.; Yu, K.; Jinno, H.; Hashizume, D.; Sekino, M.; Yokota, T.; Fukuda, K.; Tajima, K.; Someya, T., Self-powered ultra-flexible electronics via nano-grating-patterned organic photovoltaics. Nature 2018, 561 (7724), 516-+.

184. Kang, W. M.; Ma, X. M.; Hu, M.; Jia, Z. X.; Liu, H.; Cheng, B. W., Self-templating synthesis of a fluorescent porphyrin doped poly(methyl methacrylate) nano-array and its $\mathrm{HCl}$ gas sensing properties. Analytical Methods 2016, 8 (35), 6489-6493.

185. Yang, F.; Li, C.; Wei, Y. Z.; Yan, N. F.; Wang, X. H.; Liu, F.; You, S. Y.; Wang, J. Z.; Ma, W.; Li, W. W., A Simple, Small-Bandgap Porphyrin-Based Conjugated Polymer for Application in Organic Electronics. Macromolecular Rapid Communications 2018, 39 (21).

186. Kim, D.; Osuka, A., Single-Molecule Photophysical Properties of Various Directly Linked Porphyrin Arrays. Multiporphyrin Arrays: Fundamentals and Applications 2012, 1-54.

187. Park, M.; Yoon, M. C.; Yoon, Z. S.; Hori, T.; Peng, X. B.; Aratani, N.; Hotta, J. I.; Uji-i, H.; Sliwa, M.; Hofkens, J.; Osuka, A.; Kim, D., Single-molecule spectroscopic investigation of energy migration processes in cyclic porphyrin arrays. Journal of the American Chemical Society 2007, 129 (12), 3539-3544.

188. Pinkerton, N. M.; Gindy, M. E.; Calero-DdelC, V. L.; Wolfson, T.; Pagels, R. F.; Adler, D.; Gao, D. Y.; Li, S. K.; Wang, R. B.; Zevon, M.; Yao, N.; Pacheco, C.; Therien, M. J.; Rinaldi, C.; Sinko, P. J.; Prud'homme, R. K., Single-Step Assembly of Multimodal Imaging Nanocarriers: MRI and Long-Wavelength Fluorescence Imaging. Advanced Healthcare Materials 2015, 4 (9), 1376-1385.

189. Shetti, V. S.; Pareek, Y.; Ravikanth, M., Sn(IV) porphyrin scaffold for multiporphyrin arrays. Coordination Chemistry Reviews 2012, 256 (23-24), 2816-2842.

190. Dvivedi, A.; Pareek, Y.; Ravikanth, M., Sn-IV Porphyrin Scaffolds for Axially Bonded Multiporphyrin Arrays: Synthesis and Structure Elucidation by NMR Studies. Chemistry-a European Journal 2014, 20 (15), 4481-4490.

191. Mardis, K. L.; Sutton, H. M.; Zuo, X. B.; Lindsey, J. S.; Tiede, D. M., Solution-State Conformational Ensemble of a Hexameric Porphyrin Array Characterized Using Molecular Dynamics and X-ray Scattering. Journal of Physical Chemistry A 2009, 113 (11), 2516-2523.

192. Salzillo, T.; Rivalta, A.; Castagnetti, N.; D'Agostino, S.; Masino, M.; Grepioni, F.; Venuti, E.; Brillante, A.; Girlando, A., Spectroscopic identification of quinacridone polymorphs for organic electronics. Crystengcomm 2019, 21 (24), 3702-3708.

193. Xu, H.; Cao, K. D.; Ding, H. B.; Zhong, Q. F.; Gu, H. C.; Xie, Z. Y.; Zhao, Y. J.; Gu, Z. Z., Spherical Porphyrin Sensor Array Based on Encoded Colloidal Crystal Beads for VOC Vapor Detection. Acs Applied Materials \& Interfaces 2012, 4 (12), 6751-6756.

194. Cammidge, A. N.; Nekelson, F.; Hughes, D. L.; Zhao, Z. X.; Cook, M. J., Stepwise syntheses of complex mu-oxo-linked heterochromophore arrays containing phthalocyanine, porphyrin and subphthalocyanine ligands. Journal of Porphyrins and Phthalocyanines 2010, 14 (12), 1001-1011. 
195. Kang, B.; Song, E.; Lee, S. B.; Chae, B. G.; Ahn, H.; Cho, K., Stretchable Polymer Gate Dielectric with Segmented Elastomeric Network for Organic Soft Electronics. Chemistry of Materials 2018, 30 (18), 6353-6360.

196. Ferdele, S.; Jose, B.; Foster, R.; Keyes, T. E.; Rice, J. H., Strong coupling in porphyrin Jaggregate excitons and plasmons in nano-void arrays. Optical Materials 2017, 72, 680-684.

197. Yoon, M. C.; Cho, S.; Kim, P.; Hori, T.; Aratani, N.; Osuka, A.; Kim, D., Structural Dependence on Excitation Energy Migration Processes in Artificial Light Harvesting Cyclic Zinc(II) Porphyrin Arrays. Journal of Physical Chemistry B 2009, 113 (45), 15074-15082.

198. Lee, S. H.; Yang, J.; Kim, D., Structure-Dependent Electronic Interactions in Ethyne-Bridged Porphyrin Arrays Investigated by Single-Molecule Fluorescence Spectroscopy. Journal of Physical Chemistry Letters 2016, 7 (18), 3676-3682.

199. Park, S. K.; Sun, H.; Chung, H.; Patel, B. B.; Zhang, F. J.; Davies, D. W.; Woods, T. J.; Zhao, K. J.; Diao, Y., Super- and Ferroelastic Organic Semiconductors for Ultraflexible Single-Crystal Electronics. Angewandte Chemie-International Edition 2020.

200. Satake, A.; Shoji, O.; Kobuke, Y., Supramolecular array of imizazolylethynyl-zinc-porphyrin. Journal of Organometallic Chemistry 2007, 692 (1-3), 635-644.

201. Kira, A.; Umeyama, T.; Matano, Y.; Yoshida, K.; Isoda, S.; Park, J. K.; Kim, D.; Imahori, H., Supramolecular Donor-Acceptor Heterojunctions by Vectorial Stepwise Assembly of Porphyrins and Coordination-Bonded Fullerene Arrays for Photocurrent Generation. Journal of the American Chemical Society 2009, 131 (9), 3198-+.

202. Bouamaied, I.; Nguyen, T.; Ruhl, T.; Stulz, E., Supramolecular helical porphyrin arrays using DNA as a scaffold. Organic \& Biomolecular Chemistry 2008, 6 (21), 3888-3891.

203. Wang, H. W.; Chen, C. H.; Lim, T. S.; Huang, S. L.; Luh, T. Y., Supramolecular PorphyrinDABCO Array in Single- and Double-Stranded Polynorbornenes. Chemistry-an Asian Journal 2011, 6 (2), 524-533.

204. Witkowski, N., Surface and Interface Characterization in Organic Electronics. World Scientific Reference of Hybrid Materials, Vol 2: Devices from Hybrid and Organic Materials 2019, 17, 105-132. 205. Mathew, S.; Yu, J. X.; Johnston, M. R.; Quinton, J. S.; Shapter, J. G., Surface mounted porphyrin-nanotube arrays: Towards energy-harvesting surfaces. 2008 International Conference on Nanoscience and Nanotechnology 2008, 206-209.

206. Wang, S. G.; Wang, Z. W.; Li, J.; Li, L. Q.; Hu, W. P., Surface-grafting polymers: from chemistry to organic electronics. Materials Chemistry Frontiers 2020, 4 (3), 692-714.

207. Kim, T.; Kim, J.; Mori, H.; Park, S.; Lim, M.; Osuka, A.; Kim, D., Symmetry-breaking charge transfer in the excited state of directly linked push-pull porphyrin arrays. Physical Chemistry Chemical Physics 2017, 19 (21), 13970-13977.

208. Anderson, N. T.; Dinolfo, P. H.; Wang, X., Synthesis and characterization of porphyrin-DNA constructs for the self-assembly of modular energy transfer arrays. Journal of Materials Chemistry C 2018, 6 (10), 2452-2459.

209. Kanekar, D. N. N.; Chacko, S.; Kamble, R. M. M., Synthesis and investigation of the photophysical, electrochemical and theoretical properties of phenazine-amine based cyan blue-red fluorescent materials for organic electronics. New Journal of Chemistry 2020, 44 (8), 3278-3293.

210. Finnigan, E. M.; Rein, R.; Solladie, N.; Dahms, K.; Gotz, D. C. G.; Bringmann, G.; Senge, M. O., Synthesis and ligand binding properties of triptycene-linked porphyrin arrays. Tetrahedron 2011, 67 (6), 1126-1134.

211. Wang, F. L.; Tang, J. G.; Liu, J. X.; Wang, Y.; Wang, R.; Niu, L.; Huang, L. J.; Huang, Z., Synthesis and photoinduced electron transfer characteristic of a bis (zinc porphyrin)-perylene bisimide array. Journal of Physical Organic Chemistry 2011, 24 (11), 1101-1109.

212. Hao, Q. S.; Zeng, Y.; Yu, T. J.; Chen, J. P.; Yang, G. Q.; Li, Y., Synthesis and Photophysical Properties of Doubly beta-to-beta Bridged Cyclic Zn-II Porphyrin Arrays. Chemistry-an Asian Journal 2013, 8 (5), 1015-1022. 
213. Tan, K. X.; Lintang, H. O.; Maniam, S.; Langford, S. J.; Bakar, M. B., Synthesis and photophysical studies of fluorenone-armed porphyrin arrays. Tetrahedron 2016, 72 (35), 5402-5413. 214. Gotz, D. C. G.; Bruhn, T.; Senge, M. O.; Bringmann, G., Synthesis and Stereochemistry of Highly Unsymmetric beta,Meso-Linked Porphyrin Arrays. Journal of Organic Chemistry 2009, 74 (21), 8005-8020.

215. Sobral, A. J. F. N.; Justino, L. L. G.; Santos, A. C. C.; Silva, J. A.; Arranja, C. T.; Silva, M. R.; Beja, A. M., Synthesis and structural characterization of a new self-assembled disulfide linked mesotetrakis-porphyrin macromolecular array. Journal of Porphyrins and Phthalocyanines 2008, 12 (7), 845848.

216. Welsh, T. A.; Payne, A. J.; Welch, G. C., Synthesis of aromatic imide tetramers relevant to organic electronics by direct (hetero)arylation. New Journal of Chemistry 2019, 43 (24), 9333-9337.

217. Ryan, A. A.; Pouyatos, F.; Stallivieri, A.; Balaban, T. S.; Senge, M. O., Synthesis of Diazepinefused Porphyrinoids and Annulated Porphyrin Arrays. Zeitschrift Fur Naturforschung Section B-a Journal of Chemical Sciences 2014, 69 (8), 889-898.

218. Cai, H.; Fujimoto, K.; Lim, J. M.; Wang, C. J.; Huang, W. M.; Rao, Y. T.; Zhang, S. M.; Shi, H.; Yin, B. S.; Chen, B.; Ma, M.; Song, J. X.; Kim, D.; Osuka, A., Synthesis of Direct beta-to-beta Linked Porphyrin Arrays with Large Electronic Interactions: Branched and Cyclic Oligomers.

Angewandte Chemie-International Edition 2014, 53 (41), 11088-11091.

219. Ikeda, T.; Aratani, N.; Osuka, A., Synthesis of Extremely pi-Extended Porphyrin Tapes from Hybrid meso-meso Linked Porphyrin Arrays: An Approach Towards the Conjugation Length. Chemistryan Asian Journal 2009, 4 (8), 1248-1256.

220. Golf, H. R. A.; Oltmanns, A. M.; Trieu, D. H.; Reissig, H. U.; Wiehe, A., Synthesis of Functionalized BODIPYs, BODIPY-Corrole, and BODIPY-Porphyrin Arrays with 1,2,3-Triazole Linkers Using the 4-Azido(tetrafluorophenyl)-BODIPY Building Block. European Journal of Organic Chemistry 2015, (19), 4224-4237.

221. Mori, G.; Aratani, N.; Osuka, A., Synthesis of three-dimensionally arranged porphyrin arrays via intramolecular meso-meso coupling. Tetrahedron 2007, 63 (33), 7916-7925.

222. Langford, S. J.; Woodward, C. P., Synthesis, characterisation and X-ray structure of a novel porphyrin array employing $\mathrm{Zn}-\mathrm{O}$ and $\mathrm{O}-\mathrm{H}$...O bonding motifs. Polyhedron 2007, 26 (2), 338-343.

223. Maeda, K.; Nitani, M.; Uno, M., Thermocompression bonding of conductive polymers for electrical connections in organic electronics. Polymer Journal 2020, 52 (4), 405-412.

224. Bouamaied, I.; Stulz, E., Thieme Chemistry Journal Awardees - Where are They Now?

Stabilisation of Porphyrins in Tetranucleotide-Bisporphyrin Arrays by Duplex Formation with Peptide Nucleic Acid. Synlett 2009, (18), 2913-2918.

225. Wang, R. B.; Ko, C. H.; Brugh, A. M.; Bai, Y. S.; Forbes, M. D. E.; Therien, M. J., Topology, Distance, and Orbital Symmetry Effects on Electronic Spin-Spin Couplings in Rigid Molecular Systems: Implications for Long-Distance Spin-Spin Interactions. Journal of Physical Chemistry A 2020, 124 (37), 7411-7415.

226. Zhao, Z. X.; Cammidge, A. N.; Cook, M. J., Towards black chromophores: mu-oxo linked phthalocyanine-porphyrin dyads and phthalocyanine-subphthalocyanine dyad and triad arrays. Chemical Communications 2009, (48), 7530-7532.

227. Osuka, A., Towards meso-meso-Linked Porphyrin Arrays and meso-Aryl Expanded Porphyrins. Chemical Record 2015, 15 (1), 143-159.

228. Brennan, B. J.; Durrell, A. C.; Koepf, M.; Crabtree, R. H.; Brudvig, G. W., Towards multielectron photocatalysis: a porphyrin array for lateral hole transfer and capture on a metal oxide surface. Physical Chemistry Chemical Physics 2015, 17 (19), 12728-12734.

229. Brown, A.; Jeffries-El, M., Towards the development of highly conjugated BDx systems for organic electronics. Abstracts of Papers of the American Chemical Society 2018, 256.

230. Zani, L.; Dessi, A.; Franchi, D.; Calamante, M.; Reginato, G.; Mordini, A., Transition metalcatalyzed cross-coupling methodologies for the engineering of small molecules with applications in organic electronics and photovoltaics. Coordination Chemistry Reviews 2019, 392, 177-236. 
231. Yamada, Y.; Mihara, N.; Shibano, S.; Sugimoto, K.; Tanaka, K., Triply Stacked Heterogeneous Array of Porphyrins and Phthalocyanine through Stepwise Formation of a Fourfold Rotaxane and an Ionic Complex. Journal of the American Chemical Society 2013, 135 (31), 11505-11508.

232. Dahms, K.; Senge, M. O., Triptycene as a rigid, 120 degrees orienting, three-pronged, covalent scaffold for porphyrin arrays. Tetrahedron Letters 2008, 49 (37), 5397-5399.

233. Schroder, S.; Strunskus, T.; Rehders, S.; Gleason, K. K.; Faupel, F., Tunable polytetrafluoroethylene electret films with extraordinary charge stability synthesized by initiated chemical vapor deposition for organic electronics applications. Scientific Reports 2019, 9.

234. Zhu, T.; Zheng, L. Y.; Yi, C.; Yu, T. Z.; Cao, Y.; Liu, L.; Gong, X., Two-Dimensional Conjugated Polymeric Nanocrystals for Organic Electronics. Acs Applied Electronic Materials 2019, 1 (8), 1458-1464.

235. Hill, J. P.; Wakayama, Y.; Akada, M.; Ariga, K., Two-dimensional molecular array of porphyrin derivatives with bright and dark spots as a model of two-digit molecular-dot memory. Synthetic Metals 2009, 159 (9-10), 765-768.

236. Cebrian, C., Ullazine-based materials: towards novel opportunities in organic electronics. Journal of Materials Chemistry C 2018, 6 (44), 11943-11950.

237. Seong, K. D.; Kim, J. M.; Kang, J.; Hwang, M.; Lee, C.; Piao, Y., An Ultradurable and Uniform Cu Electrode by Blending Carbon Nanotube Fillers in Copper-Based Metal-Organic Decomposition Ink for Flexible Printed Electronics. Advanced Materials Interfaces 2018, 5 (16). 238. Rhee, H.; Joo, T.; Aratani, N.; Osuka, A., Ultrafast energy transfer in the soret band of linear porphyrin arrays. Ultrafast Phenomena Xv 2007, 88, 480-+.

239. Ventura, B.; Flamigni, L.; Beyler, M.; Heitz, V.; Sauvage, J. P., Unusual Photoinduced Electron Transfer from a Zinc Porphyrin to a Tetrapyridyl Free-Base Porphyrin in a Noncovalent Multiporphyrin Array. Chemistry-a European Journal 2010, 16 (29), 8748-8756.

240. Leonardi, M. J.; Palomaki, P. K. B.; Dinolfo, P. H., Using copper(I)-catalyzed azide-alkyne cycloaddition in the creation of triazole linked multi-porphyrin arrays. Abstracts of Papers of the American Chemical Society 2010, 240.

241. Bruce, R. C.; Wang, R. B.; Rawson, J.; Therien, M. J.; You, W., Valence Band Dependent Charge Transport in Bulk Molecular Electronic Devices Incorporating Highly Conjugated Multi[(Porphinato)Metal] Oligomers. Journal of the American Chemical Society 2016, 138 (7), 2078-2081. 242. Korolkov, V. V.; Svatek, S. A.; Summerfield, A.; Kerfoott, J.; Yang, L. X.; Taniguchi, T.; Watanabe, K.; Champness, N. R.; Besley, N. A.; Beton, P. H., van der Waals-Induced Chromatic Shifts in Hydrogen-Bonded Two-Dimensional Porphyrin Arrays on Boron Nitride. Acs Nano 2015, 9 (10), 10347-10355.

243. Kim, K. S.; Lim, J. M.; Osuka, A.; Kim, D., Various strategies for highly-efficient two-photon absorption in porphyrin arrays. Journal of Photochemistry and Photobiology C-Photochemistry Reviews 2008, 9 (1), 13-28.

244. Seo, D. G.; Lee, Y.; Go, G. T.; Pei, M.; Jung, S.; Jeong, Y. H.; Lee, W.; Park, H. L.; Kim, S. W.; Yang, H.; Yang, C.; Lee, T. W., Versatile neuromorphic electronics by modulating synaptic decay of single organic synaptic transistor: From artificial neural networks to neuro-prosthetics. Nano Energy 2019, 65 .

245. Zhao, P.; Zhu, L. L., Virtual special issue: Organic and polymer materials for electronics. Chinese Chemical Letters 2018, 29 (12), 1706-1708.

246. Long, J.; Xu, J. H.; Xia, S., Volatile Organic Compound Colorimetric Array Based on Zinc Porphyrin and Metalloporphyrin Derivatives. Proceedings of International Conference on Smart Grid and Clean Energy Technologies (Icsgce 2011) 2011, 12.

247. Uttiya, S.; Pratontep, S.; Bhanthumnavin, W.; Buntem, R.; Kerdcharoen, T., Volatile Organic Compound Sensor Arrays Based on Zinc Phthalocyanine and Zinc Porphyrin Thin Films. 2008 2nd Ieee International Nanoelectronics Conference, Vols 1-3 2008, 618-+.

248. Lim, Y. J.; Lee, J. H., Ytterbium Test for Water Vapor Transmission Rate Measurement of Passivation Film for Organic Electronics. Applied Chemistry for Engineering 2018, 29 (4), 484-487. 
249. Syafaat, F.; Gunlazuardi, J., Zinc-porphyrin-imide type sensitized TiO2 nanotube arrays as photoactive electrode in a dyes sensitized solar cell. International Symposium on Current Progress in Functional Materials 2017, 188.

250. Yoon, Z. S.; Easwaramoorthi, S.; Kim, D., Zn(II)porphyrin helical arrays: A strategy to overcome conformational heterogeneity by host-guest chemistry. Bulletin of the Korean Chemical Society 2008, 29 (1), 197-201. 